\title{
Preimplantation Factor (PIF) Promotes HLA-G, -E, -F, -C Expression in JEG-3 Choriocarcinoma Cells and Endogenous Progesterone Activity
}

\author{
Miya Soukaina Hakam ${ }^{a}$ Jose Maria Miranda-Sayago ${ }^{a, b}$ Soren Hayrabedyan ${ }^{c}$ \\ Krassimira Todorova ${ }^{c}$ Patrick Simon Spencer ${ }^{a} \quad$ Asma Jabeen $^{a}$ \\ Eytan Robert Barnead,e Nelson Fernandez ${ }^{\mathrm{a}}$
}

aSchool of Biological Sciences, University of Essex, Colchester, UK; ${ }^{b}$ Department of Biochemistry, Molecular Biology and Immunology, Faculty of Medicine, University of Malaga, Malaga, Spain; Institute of Biology and Immunology of Reproduction, Bulgarian Academy of Sciences, Sofia, Bulgaria; ${ }^{\text {dSIEP - }}$ Society for the Investigation of Early Pregnancy, New York, USA; ${ }^{B}$ BioIncept LLC, New York, USA

\section{Key words}

Preimplantation Factor (PIF) • HLA-G • Progesterone • Cytokines • Trophoblast • Regulation

\begin{abstract}
Background/Aims: Pregnancy success requires mandatory maternal tolerance of the semi/ allogeneic embryo involving embryo-derived signals. Expression levels of PreImplantation Factor (PIF), a novel peptide secreted by viable embryos, correlate with embryo development, and its early detection in circulation correlates with a favourable pregnancy outcome. PIF enhances endometrial receptivity to promote embryo implantation. Via the p53 pathway, it increases trophoblast invasion, improving cell survival / immune privilege. PIF also reduces spontaneous and LPS-induced foetal death in immune naïve murine model. We examined PIF effect on gene expression of human leukocyte antigen (HLA-G, $-E-F$ and $-C$ ) and the influence of PIF on local progesterone activity in JEG-3 choriocarcinoma cells. Methods: PIF and progesterone (P4) effects on JEG-3 cells surface and intracellular HLA molecules was tested using monoclonal antibodies, flow cytometry, and Western blotting. PIF and IL17 effects on P4 and cytokines secretion was determined by ELISA. PIF and P4 effects on JEG-3 cells proteome was examined using 2D gel staining followed by spot analysis, mass spectrometry and bioinformatic analysis. Results: In cytotrophoblastic JEG-3 cells PIF increased intracellular expression of HLA-G, HLA-F, HLA-E and HLA-C and surface expression of HLA-G, HLA-E and HLA-C in dose and time dependent manner. In case of $H L A-E,-F$ results were confirmed also by Western blot. Proteome analysis confirmed an increase in HLA-G, pro-tolerance FOXP3+ regulatory $T$ cells (Tregs), coagulation factors and complement regulator. In contrast, PIF reduced PRDX2 and HSP70s to negate oxidative stress and protein misfolding. PIF enhanced local progesterone activity, increasing steroid secretion and the receptor protein. It also
\end{abstract}

E.R. Barnea and N. Fernandez contributed equally to this work.

Eytan R. Barnea

and Nelson Fernández
SIEP - Society for the Investigation of Early Pregnancy, BioIncept LLC

and School of Biological Sciences, University of Essex, Colchester, (UK)

E-Mail barnea@earlypregnancy.org and nelson@essex.ac.uk 


\section{Cellular Physiology Cell Physiol Biochem 2017;43:2277-2296

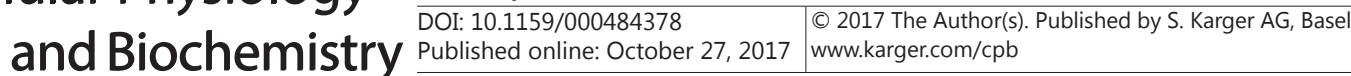 \\ Hakam et al.: Preimplantation Factor (PIF) Regulates HLA-G}

promoted the secretion of the Th1/Th2 cytokines (IL-10, IL-1 $\beta$, IL-8, GM-CSF and TGF- $\beta 1$ ), resulting in improved maternal signalling. Conclusion: PIF can generate a pro-tolerance milieu by enhancing the expression of HLA molecules and by amplifying endogenous progesterone activity. A Fast-Track clinical trial for autoimmune disease has been satisfactorily completed. The acquired data warrants PIF use for the treatment of early pregnancy disorders.

(C) 2017 The Author(s)

Published by S. Karger AG, Basel

\section{Introduction}

Mammalian pregnancy involves the successful transplant of a semi-allogeneic or allogeneic graft, whether originating through natural conception, donor embryo acceptance or cross-species embryo transfer. Paradoxically, the maternal immune system remains competent and active during pregnancy and does not reject the foetus, as it would any other transplant [1]. Embryo rejection, in fact, indicates a pregnancy complication. It is also noteworthy that autoimmune conditions, unless severe, improve during pregnancy only to recur post-partum, indicating the existence of a unique temporary immunological milieu specific to pregnancy [2-4]. Despite extensive investigations, an inclusive explanation as to why the foetus is offered special immunologic privilege has not been forthcoming $[5,6]$. It is assumed, however, that pregnancy-specific compounds play an important role [7].

Placental trophoblast cells play a key role in maintaining tolerance to the foetus [8]. Extravillous trophoblasts (EVTs), which invade the decidual stroma (interstitial invasion) and open the uterine spiral arteries [9-11], selectively express the non-classical class Ib antigens (Ag) HLA-G, HLA-E and HLA-F, and HLA-C, a non-classical class Ia Ag [10]. However, HLA-A and -B, both T-cell related HLA ligands [12] are absent from EVT, which may prevent attack by maternal cytotoxic CD8+ T lymphocytes. Progesterone (P4) promotes trophoblast invasion [13], and it increases HLA-G expression in primary trophoblasts and JEG-3 cells [14-16]. In JEG-3 cells, P4 is able to induce heterotypic associations between HLA-G and $-E$ and cell-surface expression of HLA-C, $-E$ and $-G[15,17]$. However, early in gestation P4 is of corpus luteum origin, and the level of circulating P4 is low [18]. Effective local steroid production is only taken over by the placenta by week 12 of gestation [19]. Thus, the role of pregnancy specific endogenous compound(s) in regulating trophoblast class I HLA molecules remains currently incomplete. Our premise is that immune modulation and embryo/foetus acceptance are specifically embryo-derived and embryo-driven, in coordination with the maternal immune response.

PreImplantation Factor (PIF), a small peptide secreted by viable embryos, is likely to play an important role in maternal recognition that leads to tolerance for the semi/allogenic embryo [20-22]. PIF is detectable as early as the two-cell stage and is associated with embryo development $[23,24]$. Circulating levels of PIF during early pregnancy are associated with a favourable pregnancy outcome [25]. PIF has an essentially autotrophic effect on embryo development, which is blocked by anti-PIF antibody [23]. In the embryo, PIF targets proteindisulfide isomerase/thioredoxin and heat shock proteins (HSPs), promoting embryo development and protecting against serum toxicity $[23,24,26]$. Additionally, PIF lowers natural killer (NK) cell toxicity [27]. PIF promotes endometrial receptivity to support embryo implantation [28-30]. It regulates both systemic and local maternal immunity, creating Th2 bias while preserving an effective anti-pathogenic Th1 response [31-33]. These findings have been translated to treatment of diverse immune disorders, transplantation, and brain injury models outside of pregnancy. Recently, a Fast-Track FDA clinical trial evaluating PIF for the treatment of an autoimmune disorder has been completed satisfactorily (NCT02239562) [34-41].

PIF expression in the placenta is highest shortly post-implantation, and declines around term $[20,25,42]$. A premature decline in PIF has been associated with preeclampsia and intrauterine growth retardation, thus evidencing the peptide's important role in maintaining effective placental function [41, 43]. PIF promotes invasion by extra villous cells (EVTs), without affecting these cells' proliferation $[42,44]$. This was shown with transformed 
trophoblasts and confirmed by using primary human EVTs. This in line with data showing that EVTs HLA-G+ are drivers of the immune response through their interaction with decidual immunity [45]. PIF's effect on EVTs invasion is dependent on increased metalloproteinase 9 and reduction of its inhibitor and integrin regulation. Pathway analysis demonstrated that PIF action is dependent on the MAPK, PI3K, and JAK-STAT pathways [42]. PIF acts on, and its effect is dependent on, critical apoptosis regulating the p53 pathway [46]. Relevance of the p38 MAPK/ERK signalling pathway also in polychlorinated biphenyls -induced apoptosis of human transformed EVT was reported [47]. Presently, there is limited information on local compounds that regulate HLA expression, especially during the earliest stages of pregnancy when it is most critical. Both PIF and HLA-G are secreted by viable embryos [23, 48] and interact intimately from the earliest stages of embryo development. This interaction continues, with PIF and HLA-G present in the circulation in later pregnancy. PIF and HLA-G are expressed by the trophoblast, as PIF is expressed by the viable embryo immediately post-fertilization and by the trophoblast shortly after implantation [23, 42]. Both ligands may therefore play a local regulatory role in trophoblast HLA class I function.

HLA-G expression in different trophoblastic cells was previously examined showing that JEG-3 cytotrophoblast cells expression is higher than Bewo and Jar cells [16]. In the present study, the effect of PIF on the expression of the HLA class I molecules HLA-G, -C, -E and -F in JEG-3 cells are examined using a novel and validated co-localisation and image processing approach [15]. Results were confirmed by proteome analysis. The effect of PIF was compared to that of progesterone (P4), a known HLA-G/HLA-E regulator. Whether PIF regulates endogenous P4 activity and Th1/Th2 cytokine secretion was also determined. Herein we reveal that PIF up-regulates several HLAs, potentiates progesterone action and promotes Th1/Th2 cytokine secretion by trophoblast cells. Since PIF is being tested clinically, our observations support its use for the treatment of early pregnancy disorders.

\section{Materials and Methods}

\section{Test compounds}

Synthetic PIF (MVRIKPGSANKPSDD) was obtained from Biosynthesis, Lewisville, NJ USA. Peptide had $>95 \%$ purity, documented by mass spectrometry before use. PIF was dissolved in PBS with 0.01\% dimethyl sulfoxide (DMSO) (SIGMA, Missouri, USA). Progesterone (P4) (Sigma-Aldrich, Missouri, USA) was dissolved by using absolute ethanol. IL-17RA (Life Technologies) was dissolved in Millipore water.

\section{Monoclonal Antibodies ( $m A b s$ )}

HLA-G and HLA-E antibody specificity was previously validated through FACS at the Third International Conference on HLA-G (Paris, July 2003) [49] and through separation validation studies, as reported by Palmisano [50] and Zhao [51]. [52] MEM-G/09 (EXBIO Praha, Vestec, Czech Republic), the IgG1 conformational antibody against HLA-G1 and HLA-G5, previously defined for fluorescence-activated cell sorting (FACS) and immunohistochemistry (IHC) staining, was used. For Western blotting, the MEM-G/01 (IgG1) (EXBIO Praha) clone, which recognizes the denatured HLA-G heavy chain of all isoforms, was used. For detection of the HLA-E molecule using Western blotting, MEM-E/02, (IgG1) (EXBIO Praha), which reacts specifically with all denatured HLA-E molecules and does not cross-react with HLA-A, -B, -C or -G, was used. For FACS and IHC staining, MEM-E/07 (IgG1) (EXBIO Praha), which recognizes the native surface HLA-E molecules, was used; this however is reported to cross-react with the classical MHC class I molecules HLA-B7, HLA-B8, HLA-B27 and HLA-B44. Anti-HLA-F clone 3D11 (IgG1), which recognizes the native and denatured forms of HLA-F and does not cross react with any other HLA-F type, was kindly provided by Dr. Daniel Geraghty (Seattle), and used for FACS, Western blotting and IHC staining. L31 (IgG1) (Media Pharma, Chieiti, Italy) antibody is known to bind to an epitope present on all HLA-C alleles (CW1 through to CW8), and is also known to react with HLA-B alleles (HLA-B7, -B8, -B35, -B51 and others). It was used for both FACS and microscopy, whilst the HLA-C clone D-9 (Biolegend, San Diego, CA, U.S.A) was used for Western blotting.

\section{KARGER}




\section{Cellular Physiology Cell Physiol Biochem 2017;43:2277-2296 \begin{tabular}{l|l|l}
\hline DOI: 10.1159/000484378 & $\begin{array}{l}\text { (c) 2017 The Author(s). Published by S. Karger AG, Basel } \\
\text { www.karger.com/cpb }\end{array}$
\end{tabular}}

Hakam et al.: Preimplantation Factor (PIF) Regulates HLA-G

Testing the influence of PIF and P4 on the expression of HLA class I molecules

For determining the effect of PIF and P4 on HLA class I molecule expression, JEG-3 cells were passaged and cultured at a density of $1 \times 10^{6}$ cells $/ \mathrm{ml}$ in complete medium. After $24 \mathrm{~h}$, the cells were serum starved by replacing the medium with DMEM-F12 supplemented with 0.1\% FCS. Cells were incubated for $6 \mathrm{~h}$, after which the medium was refreshed and supplemented with PIF (0-1000 nM), added for 24-72 h, or P4 (0$1 \mu \mathrm{g} / \mathrm{ml}$ ), added for $24 \mathrm{~h}$, as recently described [15]. Cells without PIF or P4, or serum free cultured cells, were used as control. The collected cells were further tested for expression for class I HLA molecules by using specific monoclonal antibodies.

Protein extraction and analysis by SDS-PAGE

Treated and untreated JEG-3 cells, following exposure to test agents were detached, counted and pelleted as described previously [14]. They were immediately lysed using SDS-lysis buffer, vortexed and heated at $95{ }^{\circ} \mathrm{C}$ for $5 \mathrm{~min}$. Cell lysates were stored at $-20{ }^{\circ} \mathrm{C}$ until used for protein analysis. To quantify the final concentration of the proteins we used the Bradford assay following the previously described protocol with some modifications [15]. Briefly, bovine serum albumin (BSA), at a concentration of $4 \mathrm{mg} / \mathrm{ml}$, was used as a calibration standard. Five $\mu \mathrm{l}$ of BSA was diluted sequentially in a 96-well microplate prefilled with PBS to produce the standard curve. Five $\mu$ of each protein sample was then diluted 1:1 with PBS and incubated with the reading reagent at room temperature for $5 \mathrm{~min}$. Finally, the protein concentration was determined using a spectrophotometer, extrapolating each absorbance value over the previously created standard curve. Samples were diluted in SDS-sample buffer, heated for $5 \mathrm{~min}$ at $95{ }^{\circ} \mathrm{C}$ and loaded onto a polyacrylamide gel (12\% resolving gel and 4\% stacking gel). The samples were run for $30 \mathrm{~min}$ at $30 \mathrm{~V}$, following increase to 100 $\mathrm{V}$ until the gel finished running. A pre-stained standard protein marker (Li-Cor Bioscience) was also loaded onto the gel and run parallel to the protein samples to be analysed.

Western blot analysis of HLAs

The proteins resolved using SDS-PAGE were then transferred onto a PVDF membrane (Immobilion Millipore Inc.), using a Mini Trans-Blot Cell (Bio Rad). Briefly, before transfer the SDS-PAGE gel was incubated in gel running buffer ( $25 \mathrm{mM}$ Tris/ $\mathrm{HCl}, 250 \mathrm{mM}$ glycine, $0.1 \%$ SDS) for $15 \mathrm{~min}$. The PVDF membrane was hydrated in absolute methanol for $10 \mathrm{~s}$ and immediately washed with molecular biology grade water. A stack consisting of sponge, Whatman paper soaked in transfer buffer $\left(20 \mathrm{mM} \mathrm{Na}_{2} \mathrm{PO}_{4}, 2 \% \mathrm{Methanol}, 0.05 \%\right.$ SDS), the PVDF membrane, the SDS-PAGE gel, Whatman paper and sponge, was then made. This stack was placed on the electro blotter and transferred to the blotting system. The transfer was done for $1 \mathrm{~h}$ at $110 \mathrm{~mA}$ and $40 \mathrm{~V}$. After transfer, the membrane was washed with molecular biology grade water and incubated in blocking buffer $(0.1 \%$ Tween, $3 \%$ dried skimmed milk and PBS) for a $1 \mathrm{~h}$ at room temperature or overnight at $4{ }^{\circ} \mathrm{C}$. After blocking, the membrane was washed and incubated with the primary monoclonal antibody for HLA-G, $-\mathrm{E}$, $-\mathrm{C}$ and $-\mathrm{F}$ overnight at $4{ }^{\circ} \mathrm{C}$. The membrane was then washed three times (10 min each wash) and incubated with secondary antibody (IRDye 800CW(C) Donkey anti-Mouse IgG from Li-Cor Biosciences) for $1 \mathrm{~h}$ at room temperature. Membranes were read using an Odyssey $C$ infrared imaging system (Li-Cor Biosciences). Semi-quantification of each antigen studied using this technique was attained by comparing loading control band (BSA) brightness and thickness using ImageJ software (http://imagej.net/).

Flow cytometry analysis of HLAs

For surface antigen expression analysis, cells were detached using Accutase and washed with PBS. Cells were counted and at least $1 \times 10^{6}$ cells were used per sample. Each sample was blocked with $0.1 \%$ BSA in PBS for $30 \mathrm{~min}$ at room temperature. For intracellular staining, after detaching and washing cells, the pellet was fixed with $4 \%$ paraformaldehyde on ice. Cells were then washed with $0.1 \%$ saponin-BSA in PBS, and permeabilized for 10 min at room temperature using $0.3 \%$ saponin in PBS.

Cells were washed with PBS and incubated with saturating concentrations of primary HLA antibodies, followed by washing and labelling with a conjugated secondary antibody. Cells were then re-suspended in $500 \mu \mathrm{l}$ of PBS and at least 10, 000 events were acquired using a BD FACS Aria I equipped with the FACS Diva software (BD Biosciences). The raw data analysis was performed using FlowJo Vx software (Tree Star Inc.).

Surface HLA antigen quantification

For surface antigen quantification, a previously described protocol was followed [15]. Briefly, we used the Qifikit beads kit (Dako). The cells were prepared following the same step as for flow cytometry up to 


\section{Cellular Physiology Cell Physiol Biochem 2017;43:2277-2296

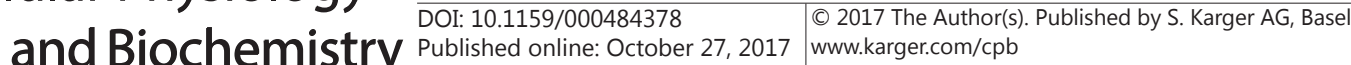

Hakam et al.: Preimplantation Factor (PIF) Regulates HLA-G

the primary HLA antibody staining stage. For detection of antibody staining cell samples, set up beads and calibration beads were all stained with FITC conjugated secondary antibody. A FACS Aria I was calibrated for the cell isotype and setup beads. A calibration curve was constructed for mean fluorescence intensity for each population of beads. The cell antigen-binding capacity was calculated by extrapolation on the calibration curve.

\section{PIF and IL-17 effect on P4 secretion}

The effect of PIF (200nM) and IL-17 (0-100 ng/ml) on P4 secretion was tested by measuring culture supernatant P4. JEG-3 cells were cultured for 24-72 h, after which supernatants were collected and kept at $-20^{\circ} \mathrm{C}$ until determining P4 levels by ELISA. Cells cultured in incomplete media (DMEM/Ham's F12) were used as controls

\section{PIF-induced HLA-G staining of JEG-3 cells}

JEG-3 cells were seeded in 8-well Lab-Tek chambers (Thermo Fisher Scientific) at a density of $8 \times 10^{3}$ per well. Cells were grown in complete medium up to $60 \%$ confluence, after which they were incubated in a serum-starved medium $(0.1 \%$ FCS $)$ for $24 \mathrm{~h}$. The cells were then treated with PIF at a concentration of $200 \mathrm{nM}$ for $24 \mathrm{~h}$ followed by fixing with $4 \%$ PFA at $4{ }^{\circ} \mathrm{C}$ and permeation with $0.25 \%$ Triton X-100 in PBS. The reaction was then treated with $2 \%$ BSA in PBS to block non-specific binding, for $1 \mathrm{~h}$ at room temperature. Cells were then incubated with the primary anti-human monoclonal antibodies anti-HLA-G (clone MEM-G/09) and anti-HLA-E (clone MEM-E/07) at a dilution of $2 \mu \mathrm{g} / 100 \mu \mathrm{l}$ in PBS for $1 \mathrm{~h}$ and anti-HLA-C (clone L31) and anti-HLA-F (clone 3D11) at a dilution of $1 \mu \mathrm{g} / 100 \mu \mathrm{l}$ in PBS for $1 \mathrm{~h}$. Cells were washed with PBS, after which they were incubated with anti-mouse IgG conjugated with Alexa Fluor 488 or Alexa Fluor 555 (Invitrogen, Carlsbad, CA, USA) at a dilution of $0.25 \mu \mathrm{g} / 100 \mu \mathrm{l}$ for $1 \mathrm{~h}$ at room temperature. Cells were washed once again and air dried. The cells were then mounted and the cell nuclei stained using Vectashield mounting medium with DAPI (Vector Laboratories, Burlingame, CA, USA), covered with coverslips (Chance proper LTD, West Midlands, England) and sealed with Marabu Fixogum rubber cement (Marabuwerke GmbH \& Co. KG, Tamm, Germany).

\section{Two-dimensional electrophoresis (2-DE) and staining}

Cell lysates and their protein concentration were prepared and assessed as previously described $[53,54]$ Frozen cell pellets were dissolved in hot lysis buffer (1\% SDS, $100 \mathrm{mM}$ Tris-HCl), and sonicated. Five percent of 2-mercaptoethanol was added. Samples were then dissolved in solubilisation buffer (8 M urea, $2.5 \mathrm{M}$ thiourea, 4\% 3-[(3-cholamidopropyl) dimethylammonio]-1-propanesuflate, $50 \mathrm{mM}$ DTT, 24mM spermine tetrachloride) at room temperature for $1 \mathrm{~h}$. The samples were centrifuged at $12000 \mathrm{xg}$ for $30 \mathrm{~min}$. To concentrate the protein samples, acetone precipitation was used. Once the supernatant was discarded the protein pellets were washed with a mixture of ice cold methanol-chloroform, and re-suspended in isoelectric focusing buffer (IEF) (8 M urea, 2.5 M thiourea, 4\% 3-[(3-cholamidopropyl) dimethylammonio]1-propanesuflate).

For first dimensional isoelectric focusing buffer (IEF), immobilized pH Gradient (IPG) dry strip gel pH 3-10NL (Bio-Rad), was rehydrated for $24 \mathrm{~h}$ at room temperature with a mixture containing $55 \mu \mathrm{g}$ of protein lysate dissolved in IEF buffer. The IPG strips were then focused using an IPGphor system (BioRad, USA). Rehydrated filter wicks were placed between the electrodes and the IPG strip. Separation of proteins in the first dimension was carried out at $20^{\circ} \mathrm{C}$ for $24 \mathrm{~h}$, following the manufacturer's protocol. After IEF, strips were rinsed in deionized water, and stored at $-80{ }^{\circ} \mathrm{C}$ until the second dimensional IEF.

For second dimensional IEF, IPG strips were incubated in equilibrium buffer 1 [6 M/l urea, 20\% w/v glycerol, 4\% w/v SDS, 0.375 M/l Tris-HCL (pH 8.8), 5\% 2-mercaptoethanol] for $15 \mathrm{~min}$ at room temperature. After that the strips were moved to equilibrium buffer 2 [6 M/l urea, 20\% w/v glycerol, 4\% w/v SDS, 0.375 M/l Tris-HCL (pH 8.8), 2.5\% 2-mercaptoethanol] and incubated for another 15 min at room temperature. Strips were then rinsed in electrophoresis buffer (60.57 g Tris base, $288.27 \mathrm{~g}$ glycine, $20 \mathrm{~g}$ SDS, double distilled $\mathrm{H}_{2} \mathrm{O}$ up to $20 \mathrm{~L}$ ). The second dimensional analysis was carried out using a Criterion gel system (BioRad). Each strip was placed into the well of a 12\% SDS-PAGE gel (Bio-Rad), and sealed with agarose solution. Electrophoresis was carried out at $50 \mathrm{~V}$ for $30 \mathrm{~min}$, and following this at $150 \mathrm{~V}$ for 4-5 h. The gel was then fixed overnight in fixing solution ( $50 \%$ methanol, $5 \%$ acetic acid, $45 \%$ water), and stained using the silver staining protocol $[55,56]$. 


\section{Cellular Physiology Cell Physiol Biochem 2017;43:2277-2296

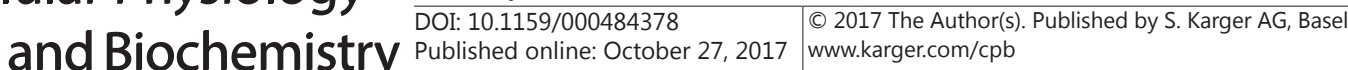

Hakam et al.: Preimplantation Factor (PIF) Regulates HLA-G

\section{Spot analysis}

The gels were scanned and analysed using SameSpots analysis software (Nonlinear dynamics Ltd). Digitized images from 12 silver stained gels were analysed for spot detection and quantification. Image analysis included spot detection, editing, background subtraction and spot matching. A master image was then created, and all spots in the other gels were matched to this master image both manually and digitally. The size of a protein, which approximates the volume of the spot, was calculated by using the software. Spots identified as differentially present were excised and analysed using mass spectrometry (MS) analysis.

\section{Mass spectrometry and bioinformatics}

Identified spots were manually excised from the 2-DE gels using a disposable sterile scalpel spot cutter and washed in molecular biology grade water. Each spot was then subjected to in gel digestion alkylation, along with tryptic digestion so as to yield peptide fragments for MS analysis following previously described protocols [57].

Peptide digests were subjected to MS analysis at the sub-picomole level through the use of a matrix assisted laser desorption ionisation-time of flight (MALDI-TOF MS) so as to generate peptide mass fingerprinting (PMF). The MALDI-TOF analysis was carried out using a Bruker Daltonics Reflex IV instrument using a linear mode with a laser power attenuation setting at 30, as described previously [58]. Once the data were examined and calibrated using the program M/Z, the results were transferred to the MASCOT peptide search engine (Matrix Science Limited) for protein identification.

\section{Differential Spot Expression Visualization}

The expression data were pre-processed by mean-centring (by division and medians), and over median normalized data. A heatmap was generated via hierarchical clustering for examining protein expression and treatment (http://cran.r-project.org). The generation of a heatmap for median centred protein expression data with horizontal hierarchical clustering of different proteins utilized the median linkage agglomeration method and vertical hierarchical clustering of treatment conditions, using complete linkage agglomeration. A correlation distance metric was used for clustering data.

Fold change of PIF treated vs. control and P4 treated vs control was applied on the raw expression data. (The spot volume data used followed the assumption that spot volume correlates and is a function of the protein expression level.) The expression ratios and the corresponding $p$-values obtained from the statistical tests applied over the differential expression data were imported into EGAN (http://akt.ucsf. edu/EGAN/). The proteins (Hugo Symnol represented) that mapped to the Entrez Genes reference were subjected to further analysis and network visualization. Selected proteins were used for related associated nodes enrichment, thus obtaining the linked annotation; GO, REACTOME, NCI-Harvard Pathways and others.

\section{ELISA for cytokine determination}

In preliminary studies, the cytokine secretion profiles of JEG-3 and ACH-P3 trophoblastic cells were determined. Subsequently, the effect of PIF and P4 on JEG-3 cell cytokines was examined, comparing against un-stimulated cell culture supernatant. At the end of the experiments the supernatant was collected and analysed for cytokine levels. The concentrations of tumor necrosis factor alpha (TNF- $\alpha$ ), interleukin (IL)1 , IL-8, IL-10, interferon gamma (IFN- $\gamma$ ), transforming growth factor beta 1 (TGF- $\beta 1$ ) and granulocyte macrophage colony-stimulating factor (GM-CSF) were measured using ELISA kits (eBioscience), following the manufacturer's instructions.

\section{Statistical analysis}

Statistical analysis was performed using the software SigmaPlot version 12.5 (Systat Software Inc., India). The descriptive statistics and normality test were done as a first step. If the population followed a normal distribution (Gauss' Bell), Student's t-test was used to compare the different groups (treated vs. non-treated, surface $v s$. intracellular antigen expression, etc.). If the population did not follow a normal distribution Mann-Whitney U test was used. The multiparametric comparison was performed by ANOVA. The $\mathrm{p}<0.05$ value is considered significant. 


\section{Results}

\section{PIF's effect on JEG-3 cells: HLA-G expression}

PIF promotes trophoblast invasion and protects against apoptosis [46]. Whether PIF is involved in regulating HLA class I antigen expression to promote maternal tolerance is not known. The viable embryo secretes both PIF and soluble HLA-G into the culture media [16, 48]. PIF promotes invasion, regulates the immune response and has anti-apoptotic effects. Since PIF is expressed by the trophoblast shortly post-implantation its potential regulatory role on local HLA class I molecules was examined. This is relevant for understanding the development of tolerance from the earliest stages of gestation.

The effect of synthetic PIF (1--1000 nM) on HLA-G expression in JEG-3 cells was determined by using serum free media. JEG-3 cells are here shown to be superior to ACH-3P and therefore were used for all experiments in the current study [52]. This was substantiated by the following observations. 1. ACH-3P cells are comprised of two populations of cells, however only in $40 \%$ of the cells HLA-G+ is expressed [52]; 2. The expression of HLA-C, -E, F, G is higher in JEG-3 cells than in ACH-3P cells [52]:; 3. HLA-C was only expressed in JEG-3 cells. 4. IL- $1 \alpha$, IL-8, IL-10 and TGF- $\beta 1$ levels were higher in JEG-3 cells than in ACH-3P cells [52].

To validate measurements of the mean fluorescence intensity (MFI) a calibration curve was constructed, plotting against antigen binding capacity. For validating the MFI binding target data, a double logarithmic graph was used to provide the best fit, $\mathrm{R}^{2}=0.99$ (Fig. 1). This methodology was used in all subsequent experiments.

PIF was found to increase HLA-G levels in JEG-3 cells in a dose-dependent manner (Fig. 2A). PIF promoted HLA-G expression at all concentrations tested (up to $1 \mathrm{uM}$ ). The highest effect was noted testing PIF at 200nMconcentration. In the time course experiment, $200 \mathrm{nM}$ PIF added for $24 \mathrm{~h}$ in culture induced the most pronounced increase in HLA-G expression (28 fold) (Fig. 2B). This supports the hypothesis that PIF's role is to be a driver of tolerance.

The effect of PIF on HLA class I antigen expression by JEG-3 cells

HLA molecules are expressed both intracellularly and on the cell surface. The effect of PIF on intracellular HLA-G, $-\mathrm{E},-\mathrm{F}$ and $-\mathrm{C}$ expression by JEG-3 cells was determined (Fig. 2C). PIF increased the expression of all tested HLAs. HLA-G exhibited the highest level of expression followed by HLA-E. The increase in intracellular expression was coupled with an increase of cell surface HLA-G and HLA-E ( $\mathrm{p}<0.01$ ) (Fig. 2D). HLA-C expression also increased on the cell surface $(p<0.05)$. However, PIF only minimally affected surface HLA-F expression. The time-dependent increase in HLA-F and HLA-E expression was confirmed using Western blotting, which demonstrated that the maximal increase was already attained at $24 \mathrm{~h}$ of culture (Fig. 3A-D) Thus, PIF activates class I HLA molecules.

PIF and P4 have a differential effect on HLA class I expression by JEG-3 cells

JEG-3 cells cultured with $1 \mu \mathrm{g} / \mathrm{ml} \mathrm{P} 4$ for $24 \mathrm{~h}$ produced increased levels of HLA-G, -E, $-F$ and $-\mathrm{C}$, with HLA-G expression being the most pronounced (Fig. 4A). Intracellular

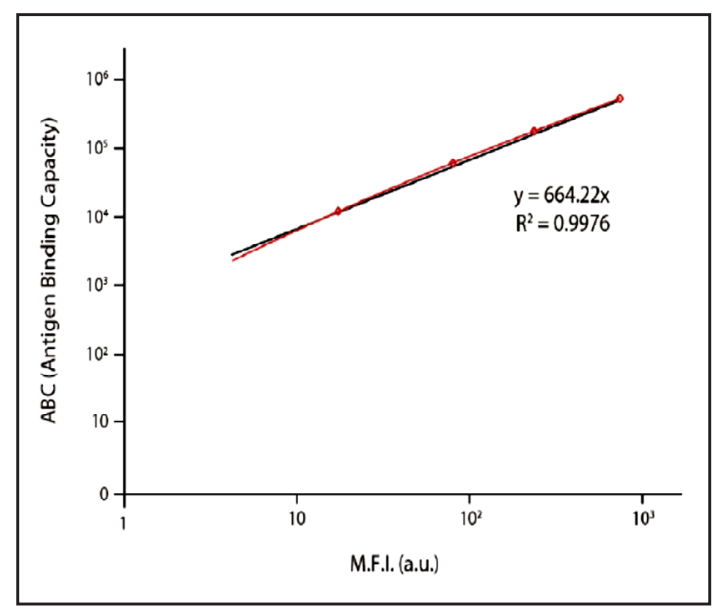

Fig. 1. Bead population MFI calibration versus antigen binding capacity. In order to determine the level of expression of each antigen, as tested by using MFI, a calibration curve was set up. The vertical axis reflects the antigen-binding capacity, which is plotted against the horizontal axis MFI. The calculation is based on the best fit where $\mathrm{R}^{2}=0.99$. 


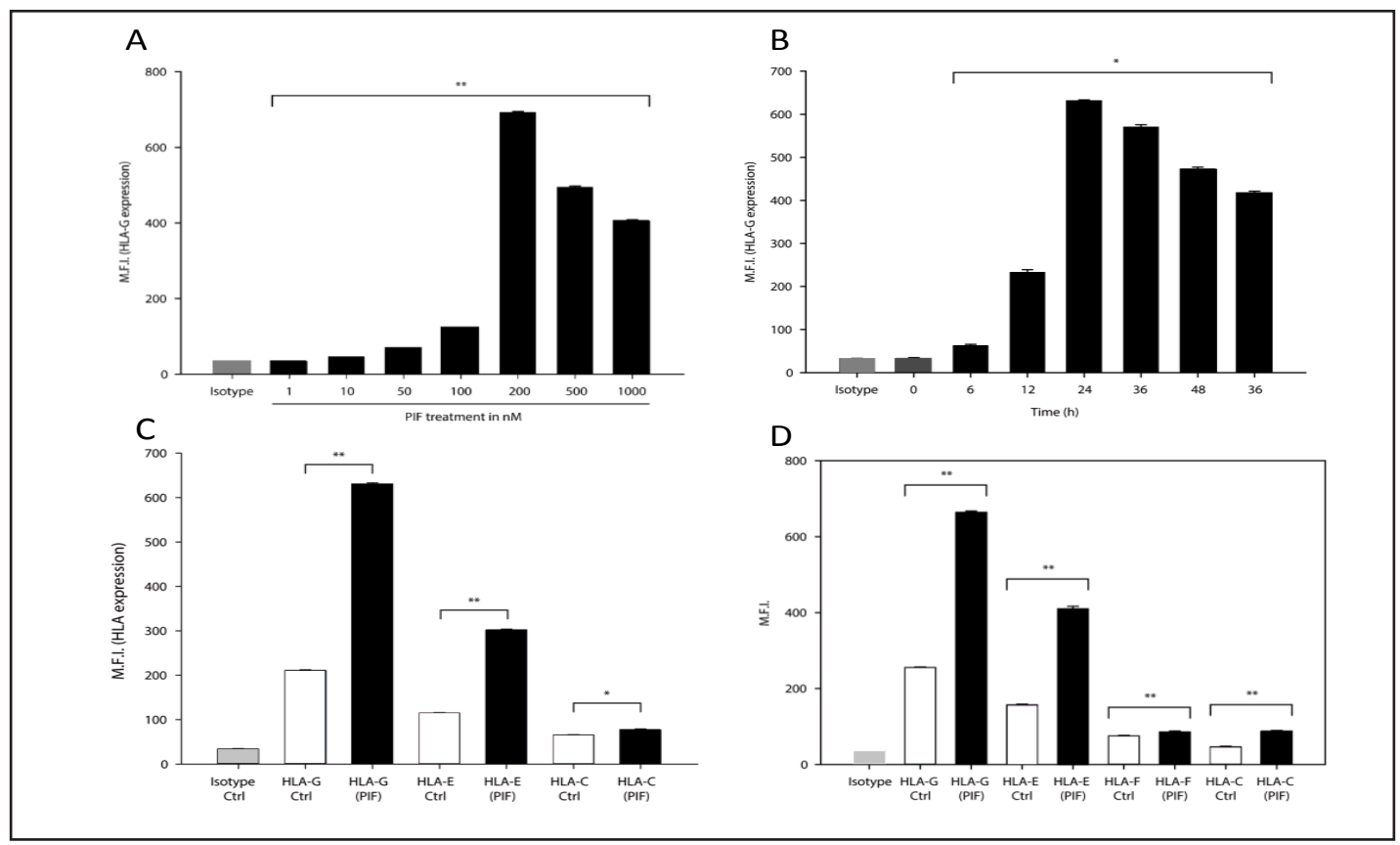

Fig. 2. Effect of PIF on HLA class I molecule expression by JEG-3 cells. The effect of PIF (1-1000nM) on HLA class I expression by JEG-3 cells, after $0-72 \mathrm{~h}$ of culture, was determined by Western blotting and flow cytometry using isotype as control. A. Results showed that PIF increased HLA-G expression in JEG-3 cells, attaining maximal effect at a concentration of 200nM. B. The maximal effect of PIF was noted at $24 \mathrm{~h}$ of incubation. C. PIF at 200nM and $24 \mathrm{~h}$ incubation promoted the expression of HLA-G, HLA-E, and slightly increased HLA-C expression cell surface. D. PIF at 200nM and $24 \mathrm{~h}$ incubation promoted the expression of HLA-G, HLA-E, moderately increasing HLA-C and HLA-F expression intracellularly. The data are mean \pm SE of triplicates repeated three times. ${ }^{*} \mathrm{p}<0.05,{ }^{* *} \mathrm{p}<0.01$.

Fig. 3. Cell surface expression of HLA-F and HLA-E induced by PIF at 200nM PIF, with stimulation at 4, 12, 24, 48 and 72 h. Western blotting A. Total protein expression of HLA-F, as induced by PIF stimulation. B. Cell surface expression of HLA-F, as induced by PIF. C. Total protein expression of HLA$\mathrm{E}$, as induced by PIF stimulation. D. Cell surface expression of HLA-E, as induced by PIF. For each experiment, controls used were only cell samples.

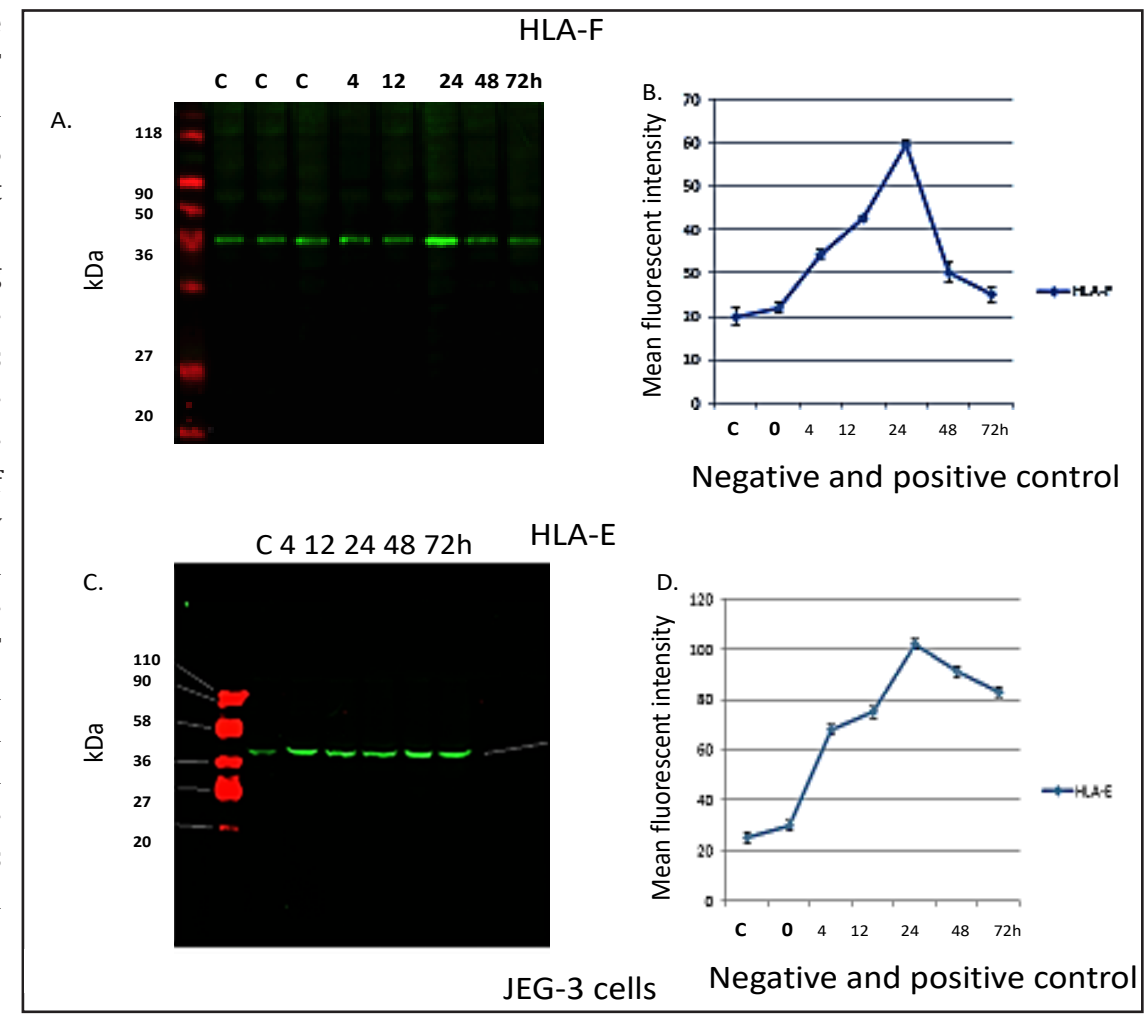


A.

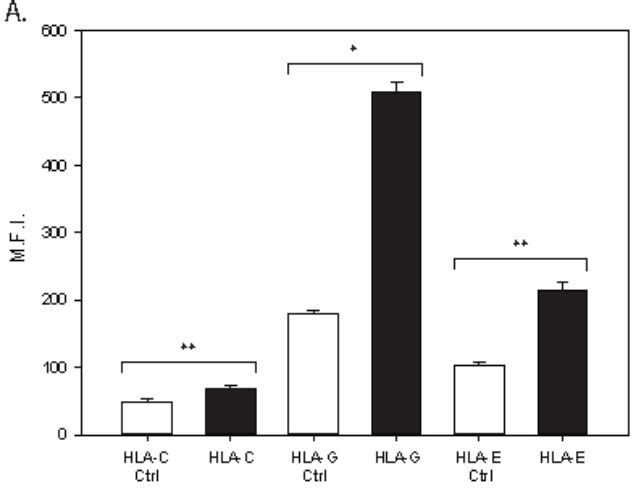

B.

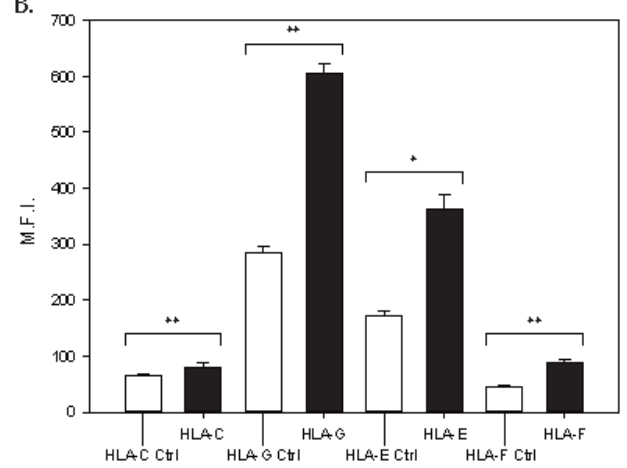

C.

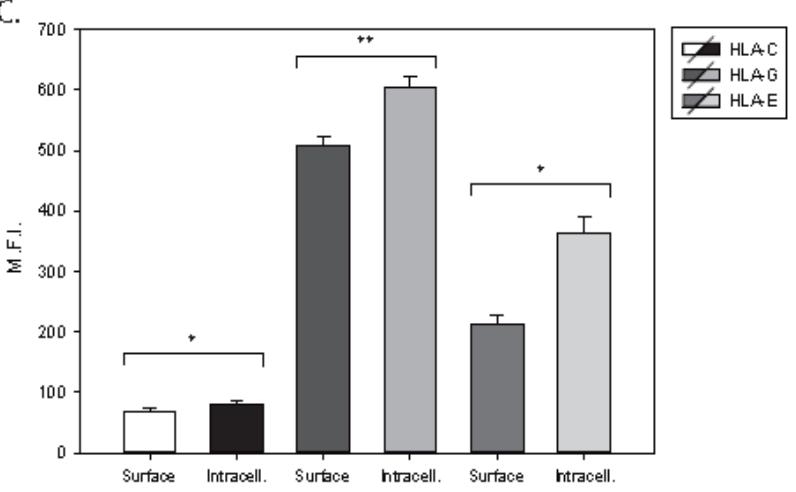

Fig. 4. Progesterone promotes HLA class I molecule expression by JEG-3 cells. The effect of P4 on HLA I subtypes was examined in JEG-3 cells using the maximally effective P4 concentration $1 \mu \mathrm{g} / \mathrm{ml}$, with cells cultured for $24 \mathrm{~h}$. Data were analysed by Western blotting and flow cytometry. A. Data showing that P4 increased production of all tested HLA antigens intracellularly, HLA-G being the most increased ligand followed by HLA-E. B. P4 induced significant HLA-C, -E, -F and -G expression on the cell surface. C. Data demonstrating that HLA expression was higher in the intracellular domain as compared to an extracellular location. ${ }^{*} \mathrm{P}<0.01,{ }^{*} \mathrm{P}<0.05$, mean+/-SEM.

and surface measurements demonstrated significant P4-induced HLA expression (Fig. 4B, 4C). Significant differences between intra- and extracellular HLA expression were noted. The highest increase was noted with HLA-G, followed by HLA-E and a mild effect was observed on HLA-C expression (Fig. 4C). This confirmed that the $1 \mu \mathrm{g} / \mathrm{ml}$ dose at $24 \mathrm{~h}$ was most effective. This observation permitted comparison of the effect of PIF with the most effective concentration of $\mathrm{P} 4$.

The effect of $200 \mathrm{nM}$ PIF was compared with $1 \mu \mathrm{g} / \mathrm{ml} \mathrm{P} 4$ after incubation for $24 \mathrm{~h}$. Western blot analysis showed that, compared to P4, PIF induced increase was more pronounced in both HLA-G and HLA-E expression $(p<0.01)$. Basal expression of HLA-C and HLA-F was low. However, PIF induced a higher expression of both ligands as compared to P4 (Fig. 5A). Flow cytometry analysis and the antigen quantification data confirmed the Western blot data. The PIF-induced increase in both intracellular and surface HLA expression was also more pronounced compared to the effect of P4 (Fig. 5B). The most pronounced effect noted was on HLA-G and HLA-E expression (Fig. 5C). The increase in HLA expression at the intracellular level translated to an increase at the surface level, with PIF-treated cells displaying high MFI and surface antigens in comparison to P4-treated cells.

\section{PIF promotes $P 4$ secretion}

PIF promoted the expression of IL-17F, a pro-inflammatory cytokine in the trophoblast that plays an important role in angiogenesis [46]. Using a dose-dependent design, 1-100 


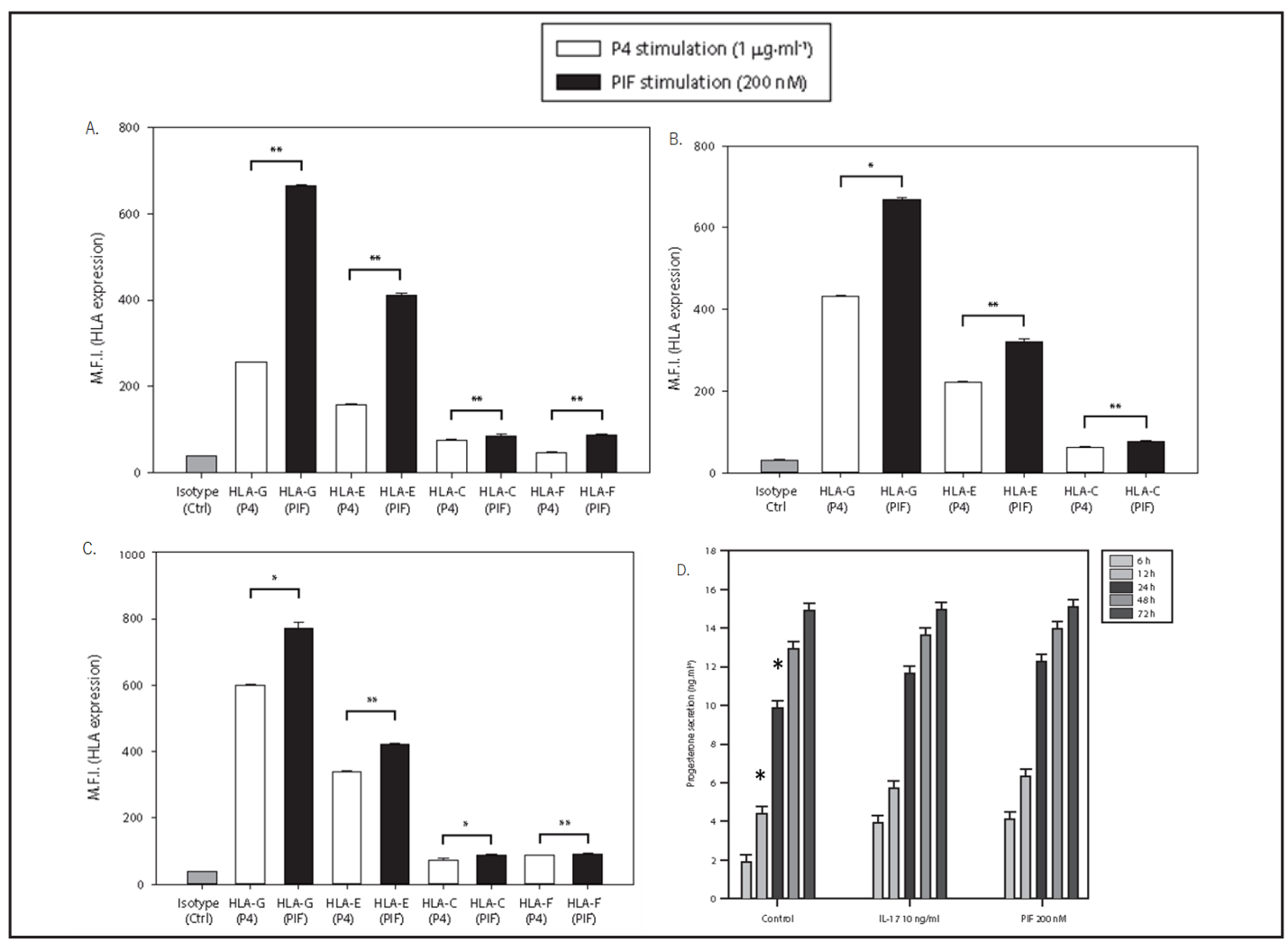

Fig. 5. The effect of PIF and P4 on HLA class I antigen expression, and the effect of Il-17 on P4 secretion by JEG-3 cells. The effect of 200nM PIF on HLA class I expression by JEG-3 cells was compared with that of $1 \mu \mathrm{g} / \mathrm{ml} \mathrm{P4}$, using Western blotting and flow cytometry. The effect of 200nM PIF and 10ng/ml IL-17 on P4 secretion by JEG-3 cells was also tested, using ELISA, after cells were incubated for 6-72 h. A. PIF induced a significant increase in HLA-G and HLA-E as compared to P4. The effect of PIF on HLA-C and F expression was mild. B. PIF had a greater effect than P4 in promoting HLA class I intracellular expression. C. PIF increased the expression of HLA class I molecules on the cell surface, particularly HLA-G and HLA-E expression. D. Both IL17 and PIF increased P4 secretion by JEG-3 cells in a time dependent manner. ${ }^{*} \mathrm{P}<0.05,{ }^{* *} \mathrm{P}<0.01$.

$\mathrm{ng} / \mathrm{ml}$ IL-17 promoted P4 secretion by JEG-3 cells, as determined by ELISA. The maximal effect was noted at $10 \mathrm{ng} / \mathrm{ml} \mathrm{IL-17} \mathrm{(} \mathrm{p}<0.01$ ) (data not shown). Both 200nM PIF and 10ng/ $\mathrm{ml} \mathrm{IL-17,} \mathrm{after} \mathrm{6-72} \mathrm{h} \mathrm{of} \mathrm{culture,} \mathrm{increased} \mathrm{P4} \mathrm{secretion} \mathrm{by} \mathrm{JEG-3} \mathrm{cells,} \mathrm{observed} \mathrm{at} 6$ and 24 h, respectively. (Fig. 5D). Thus, PIF directly promotes P4 secretion through an IL-17dependent pathway.

\section{Imaging analysis confirms that PIF promotes HLA-G expression}

Following culture of JEG-3 cells until confluence, the cells were washed and cultured in serum-free media in the presence of 200nM PIF. The effect of PIF on HLA-G expression was examined after $24 \mathrm{~h}$ of incubation. It was found that the expression of HLA-G in PIF-treated JEG-3 cells (anti-HLA-G mAb stained) increased (Fig. 6). Further, DAPI staining revealed an intact nuclear structure. This provided additional evidence that PIF promotes HLA-G expression.

The effect of PIF and P4 on protein levels in JEG-3 cells

To determine whether PIF also regulates the placental proteome, the effect of $200 \mathrm{nM}$ PIF and $1 \mu \mathrm{g} / \mathrm{ml} \mathrm{P} 4$ on protein expression by JEG-3 cells was analysed by 2 -DE gel electrophoresis. Proteins were separated in the first dimension based on their pI, which ranged from 3-10, and, based on their size, by SDS-PAGE in the second dimension. The analysis of the master gel detected 22 spots showing differences between treatment and control cells. 


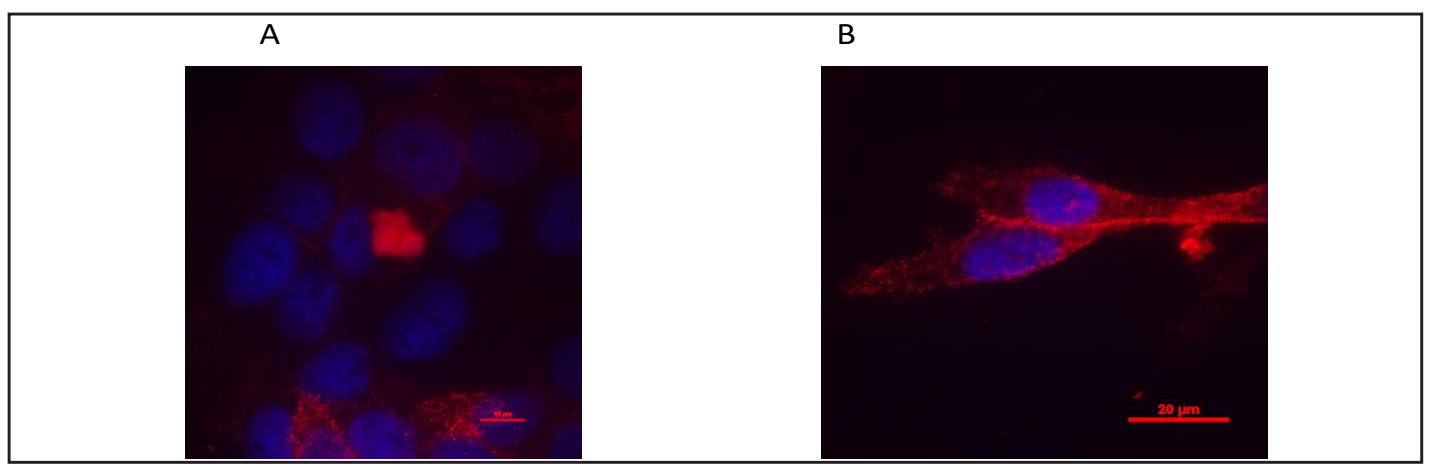

Fig. 6. Image analysis demonstrating PIF-induced up-regulation of expression of HLA-G in JEG-3 cells. Up-regulation of cell surface expression, as determined by confocal microscopy analysis. Acquisition was carried out in stacks, resulting in 3-D images. A. Cell only sample. B. PIF-treated sample. Red, anti-HLA-G antibody; blue, DAPI stain. See methods for additional details.

Table 1. Effect of PIF and P4 on proteins detected by 2-DE and mass spectrometry. All results are given in $\mathrm{pg} / \mathrm{ml}$. Results shown are mean \pm SEM from six independent experiments ${ }^{*} \mathrm{P}<0.05$

\begin{tabular}{|c|c|c|c|c|c|c|c|c|}
\hline & \multirow{2}{*}{ Spot } & \multirow{2}{*}{ ANOVA (P) } & \multirow{2}{*}{ Fold } & \multirow{2}{*}{$\begin{array}{c}\text { Protein Accession Number } \\
\text { (UniProt) }\end{array}$} & \multirow{2}{*}{$\begin{array}{l}\text { Protein } \\
\text { name }\end{array}$} & \multicolumn{3}{|c|}{ Average Normalised Volumes } \\
\hline & & & & & & Control & P4 & PIF \\
\hline \multirow{17}{*}{ 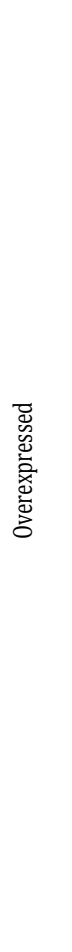 } & 67 & $>0.001$ & 2.3 & Q96PD2 & DCBD2 & 243.571 & 413.865 & 566.578 \\
\hline & 51 & 0.001 & 2.6 & P13987 & CD59 & 150.222 & 388.079 & 310.118 \\
\hline & 55 & 0.002 & 2.5 & P06401 & PRGR & 246.889 & 277.710 & 625.968 \\
\hline & 98 & 0.007 & 1.5 & Q9BZS1 & FOXP3 & 732.057 & 1035.457 & 1129.905 \\
\hline & 71 & 0.015 & 2.1 & P06576 & АТР5B & 132.881 & 283.644 & 207.615 \\
\hline & 92 & 0.016 & 1.7 & P68871 & HBB & 394.897 & 544.421 & 653.066 \\
\hline & 89 & 0.019 & 1.7 & P17693 & HLAG & 733.573 & 961.078 & 1248.309 \\
\hline & 32 & 0.023 & 2.9 & & & 132.122 & 123.015 & 359.905 \\
\hline & & & & P26651 & TTP & & & \\
\hline & 69 & 0.027 & 2.2 & 095833 & CLIC3 & 326.428 & 220.958 & 484.635 \\
\hline & 8 & $>0.001$ & 3.9 & 095757 & HS74L & 431.610 & 407.206 & 111.996 \\
\hline & 24 & 0.001 & 3.3 & P30101 & PDIA3 & 508.002 & 425.280 & 155.610 \\
\hline & 2 & 0.002 & 4.4 & P08107 & HSP71 & 601.820 & 328.658 & 136.959 \\
\hline & 30 & 0.002 & 3.0 & P00533 & EGFR & 498.008 & 313.949 & 166.079 \\
\hline & 66 & 0.003 & 2.3 & P32119 & PRDX2 & 220.649 & 144.399 & 94.620 \\
\hline & 34 & 0.004 & 2.9 & P02545 & LMNA & 349.317 & 276.712 & 121.548 \\
\hline & 84 & 0.005 & 1.8 & P13639 & EF2 & 971.456 & 578.216 & 535.644 \\
\hline \multirow{3}{*}{ 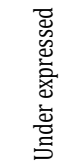 } & 75 & 0.015 & 2.0 & P14618 & KPYM & 1299.172 & 1078.025 & 649.914 \\
\hline & 81 & 0.016 & 1.9 & P16422 & EPCAM & 455.831 & 294.987 & 245.081 \\
\hline & 87 & 0.018 & 1.7 & P04406 & G3P & 510.311 & 399.647 & 294.760 \\
\hline
\end{tabular}

A comparison of the average spot volume (mean $\pm \mathrm{SD}, 4$ samples/group) of the 22 spots was carried out. Significant differences between PIF-treated and untreated JEG-3 cells were found. Fourteen spots from the PIF-treated group decreased, whereas nine significantly 


\section{Cellular Physiology Cell Physiol Biochem 2017;43:2277-2296

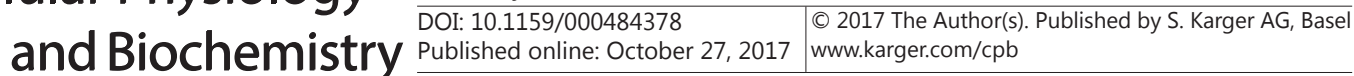 \\ Hakam et al.: Preimplantation Factor (PIF) Regulates HLA-G}

increased. Comparison of P4-treated cells with PIF's effect was also significant. The 22 protein spots identified by mass spectrometry analysis were validated by using a ProFound probability score of 0.99-1.00. Since not all spots could be confirmed further, bioinformatic and pathway analysis was performed only on the 19 validated proteins (Table 1).

\section{Bioinformatic analysis of proteomic data}

Fig. 7 shows the heat map visualized effect of PIF on the placental proteome. GO analysis of the biological functions of the 19 significant proteins showed that they are mainly related, in terms of response to stimulus, regulation of biological process, multicellular organismal process, cell communication, developmental process and cell proliferation. The proteomic data confirmed that PIF-induced an increase in HLA-G, validating the antibody based data. FOXP3+, an activation marker of pro-tolerance Tregs, also increased. Remarkably, PIF increased the P4 receptor (PRGR, 2.5 fold) protein coupled with the increase in P4 secretion (see above) which potentiates P4 action in trophoblasts. In addition, PIF increased levels of pro-coagulation factors DCBD2 V/VIII-Homology domain, TTP, Von Willebrand FactorCleaving Protease and CD59, involved in complement regulation. ATP5B, which is $\mathrm{H}+$ transporting, mitochondrial F1 complex and ZSC21, a potent transcriptional activator, and CLIC3 and HBB, were overexpressed as well.

In contrast, proteins involved in oxidative stress and protein misfolding were reduced, including PDIA3, protein disulfide isomerase A3, PRDX2 peroxiredoxin-2, HS74L, (HSP704)- and HSP71 (HSP70-8). These are prime PIF targets which are also regulated in vivo [26, 33, 37]. Mitogenic effects of EGF were reduced by lowering its receptor levels, which is likely to support trophoblastic differentiation. Also, EPCAM, calcium-independent cell adhesion and LMNA and EF2 proteins were decreased, which catalyse the GTP-dependent ribosomal translocation step. Metabolic KPYM pyruvate kinase and G3P glycerol-3-phosphate dehydrogenase- 1 proteins were decreased as well. Thus PIF, in contrast to P4, has a dual regulatory and protective action.

\section{Hierarchical clustering analysis}

The detected differentially expressed proteins were analysed, using hierarchical clustering of normalized protein expression and treatment conditions (PIF vs. P4) and Explora-

Fig. 7. Heatmap of protein expression and hierarchical clustering of the proteins and treatment. Heatmap of median centred protein expression data with horizontal hierarchical clustering of different proteins using the median linkage agglomeration method and vertical hierarchical clustering of treatment conditions using complete linkage agglomeration. Correlation distance metric was used for clustering data.

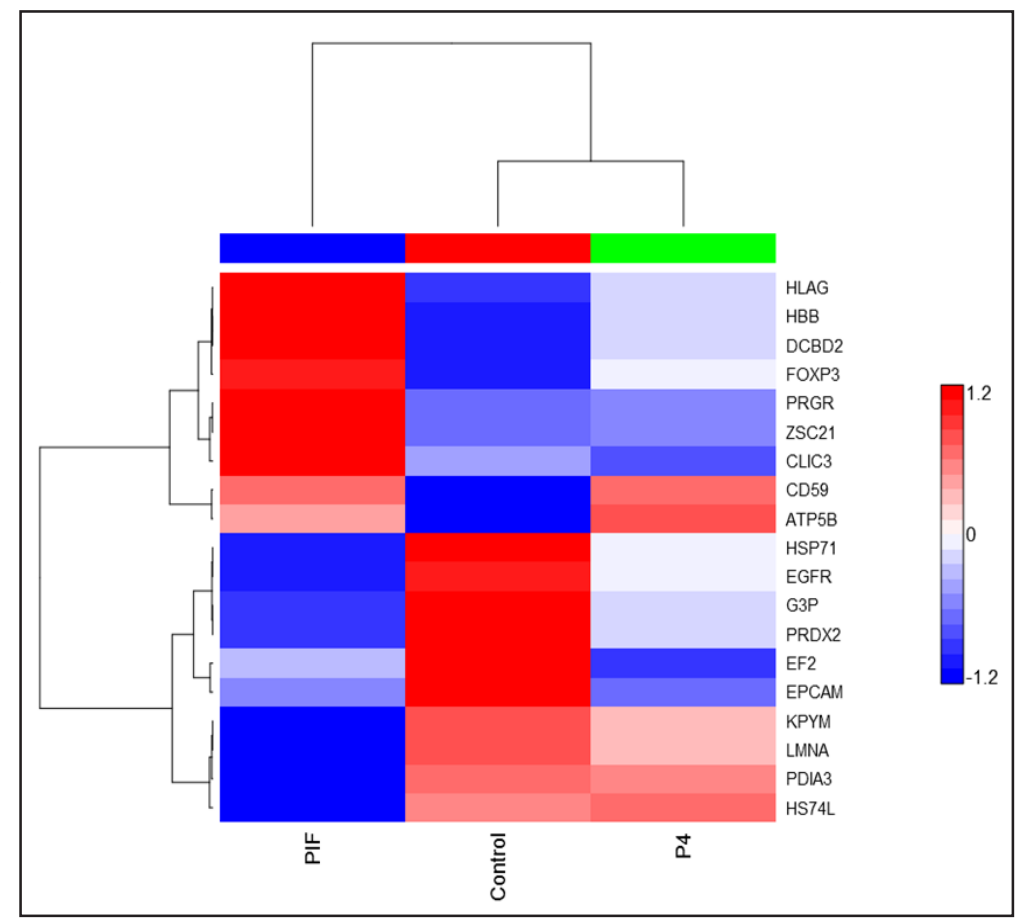


Fig. 8. Exploratory Gene Association Networks analysis of PIF and P4: treated vs non-treated control cells. Protein-protein interaction and protein annotation are depicted in network linkage fashion, where upregulated proteins are indicated with a red border and down-regulated proteins with a green border. Border width is proportional to protein differential expression probability. GO and NCI-Nature Pathway Annotations are depicted and colour coded. The heatmap represents fold expression compared to control. CLIC3 is the only quality difference, being up-regulated by PIF and down-regulated by $\mathrm{P} 4$, when compared to control.

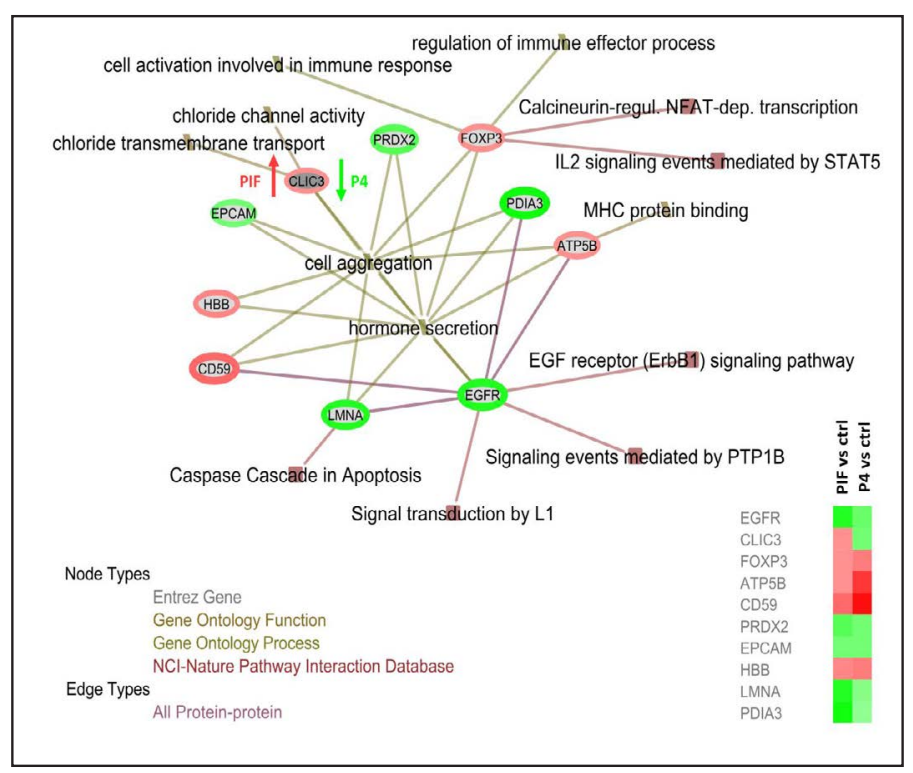

tory Gene Association Networks (EGAN) analysis to explore the involvement of PIF in differentially expressed networks. Hierarchical clustering revealed that PIF reciprocally down-regulated half the proteins compared to control cells. It also triggered up-regulation in nine cases, in contrast to P4.The top up-regulated cluster was ranging from HLAG to FOXP3. On the other hand, P4 up-regulated only five of 19 differentially expressed proteins, with the remaining down-regulated (Fig. 8).

When EGAN was applied, the CLIC3 protein differed only in terms of its expression mode, since PIF up-regulated while P4 down-regulated the same protein. This protein is a voltage-dependent chloride ion channel and participates in cell membrane potential stabilization. The increase in CLIC3 may protect against intrauterine growth retardation and preeclampsia, since PIF expression is low in this condition [46, 59]. EGAN performs a hypergeometric enrichment of linked annotations to the gene-related nodes, and in the case of PIF treatment, FOXP3 is up-regulated and linked to NFAT transcriptional control, while PDIA3 is linked to oxidative stress and calcium signalling, which is decreased. Similarly, several pathways and processes are affected by EGFR down-regulation, with few selected and represented, for example for signal transduction mediated by PTPB1, by IL1 and the related protein-protein interaction of EGFR with LMNA (increased Apoptosis related Caspases). PDIA3 (increased calreticulin based calcium signalling) and ATPB5 (decreased MHC protein binding) are also targeted by PIF [26]. Thus, proteome data confirms PIF's promoting effect on HLA-G and the P4 receptor while reducing oxidative stress and protein misfolding.

The effect of PIF and P4 on the cytokine profile of JEG-3 cells

Since PIF was effective in promoting HLA expression, particularly that of HLA-G, we examined whether such stimulation also extends to an effect on the production of cytokines needed to interact with the maternal milieu. The effect of 200 nM PIF on JEG-3 cell cytokine KARGER 


\section{Cellular Physiology Cell Physiol Biochem 2017;43:2277-2296

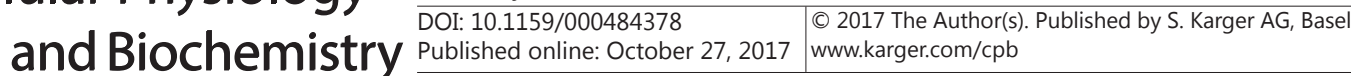 \\ Hakam et al.: Preimplantation Factor (PIF) Regulates HLA-G}

secretion was compared with $1 \mu \mathrm{g} / \mathrm{ml} \mathrm{P} 4$ using serum-free media for $24 \mathrm{~h}$. PIF increased production of both clinically relevant Th1 and Th2 type cytokines (IL-10, IL-1 $\beta$, IL-8, GM-CSF and TGF- $\beta 1$ ). In contrast, P4 only increased IL-10 secretion (Table 2). The results show that PIF induces a balanced secretion of cytokines, promoting tolerance whilst sustaining antipathogen protection. However, the effect of P4 is limited.

\section{Discussion}

Consistent with a prior study, the expression levels of HLAs and secreted cytokines in JEG-3 cells were superior to those in ACH-3P cells and the JEG-3 cell line was herein used [14]. We demonstrate that in JEG-3 cells PIF up-regulates the pivotal pro-tolerance molecule HLA-G and the associated class I molecules HLA-C, -E and -F. Proteome analysis confirmed up-regulation of HLA-G, pro-tolerance Tregs (FoxP3+), coagulation factors and complement, and the reduced expression of proteins involved in oxidative stress and protein misfolding. Reduced EGF receptor expression may limit the proliferative potential of the trophoblast. PIF's promoting effect on all of the HLAs and cytokines studied was more pronounced than P4's. Evidence for PIF-induced amplification of endogenous P4 action is shown by increased P4 secretion coupled with increased steroid receptor protein levels.

HLA and cytokine expression in JEG-3 cells creates a balance between a pro-inflammatory and anti-inflammatory environment. PIF increased HLA-G, HLA-E and HLA-C expression both intracellularly and at the cell surface, as evidenced by complementary methods of analysis. HLA-G up-regulation was confirmed by using HLA-G imaging and proteome analysis. Such robust multifaceted analyses provide support for PIF's important local regulatory role. The PIF-induced increase in HLA-E expression was of similar magnitude to HLA-G. The role of HLA-E at the feto-maternal interface can be complementary to HLA-G. Both can be coexpressed and induced by $\mathrm{P} 4$ in the trophectoderm of preimplantation embryos $[15,16]$. Recognizing P4's important role in HLA regulation, a direct comparison with that of PIF shown confirmed PIF's higher efficacy in all side-by-side experiments. Both PIF and P4 increased intracellular and cell surface expression of HLA-G, -E, -F, and -C, but did not affect their relative proportion. This may be critical for a successful pregnancy; while not all HLA-G molecules need to form a heterodimer with HLA-E, the lack of heterodimer formation of HLA-E, combined with HLA-G, can lead to implantation failure [60]. Moreover, for its surface expression, HLA-E must interact with and be stabilized by a signal peptide, usually derived from other HLA class I alleles. In trophoblasts, it is derived from HLA-G and HLA-C [61]. HLA-E can also interact with uNK cells through the CD49/NKG2 receptor [62]. Together, HLA-G and HLA-E may inhibit NK cells cytotoxicity by interacting with the killer-cell immunoglobulinlike receptors (KIR)2DL4 and CD94/NKG2, respectively. Trophoblast protection from cell lysis is also achieved through interaction of HLA-G homodimers with the inhibitory NK receptors ILT2 and ILT4 [15]. Both PIF and P4 increased HLA-C expression, which also targets KIR molecules on uNK cells. KIR molecules regulate trophoblast invasion and uterine spiral artery blood flow in the inter-villous space [63]. Certain maternal KIR/HLA-C combinations can lead to defective trophoblast invasion or to an incomplete transformation of the spiral arteries, ultimately leading to pregnancy complications [60,63]. The involvement of RAC1 and downstream b-catenin role in effective trophoblast invasion by promoting metalloproteinase 9 (MMP-9) was shown [64]. PIF also promoted MMP9 while reducing the inhibitor TIMP1 and regulating integrins expression [42]. Thus, the low PIF expression in preeclampsia and intrauterine growth retardation may lead to the low local MMP-9 expression $[42,46]$. In addition, detailed proteomic analysis of syncytiotrophoblast extracellular vesicles identified differentially expressed proteins in the placenta of patients with preeclampsia among them increased pro-inflammatory S100-A8 as having a major role [65]. Also, it was shown that thrombin is an inducer of FMs-like tyrosine kinase 1 through increased ROS in transformed EVT supporting role in preeclampsia pathogenesis [66]. Importantly, we reported that in 


\section{Cellular Physiology Cell Physiol Biochem 2017;43:2277-2296

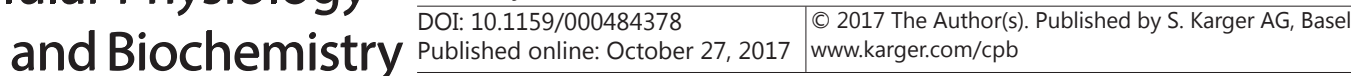 \\ Hakam et al.: Preimplantation Factor (PIF) Regulates HLA-G}

human immune cells PIF targets both thrombin and S100-A8, thus through local action PIF could mitigate such pathology [33]. PIF reduced systemic NK cells cytotoxicity and up-regulated local HLA-C expression, suggesting an integrated protective action [37]. PIF and P4 only mildly affected HLA-F expression, confirming previous observations [14]. PIF is expressed in trophoblasts during the earliest phase of gestation and is also present in maternal circulation nine days after insemination. Therefore, both endogenous and exogenous PIF may regulate trophoblastic HLA-G. Collectively, the observed potent PIFinduced up-regulation of HLA in trophoblasts reveals an essential role for PIF in promoting immune tolerance.

Our 2-DE proteome analysis demonstrated the PIF-induced increase in P4 receptor levels in JEG-3 cells, coupled with increased P4 secretion [53, 54]. This reveals PIF's important role in endogenous $\mathrm{P} 4$ potentiation, which thus may facilitate the steroid's production overtake by the placenta. The stimulatory effect of hCG on the corpus luteum as well as on endogenous (trophoblast) P4 was also reported [67]. The PIF data also confirmed the increase in HLA-G and FOXP3, a marker of Treg activation, serving to amplify the protolerance effect. Circulating Tregs increase prior to implantation in response to the presence of a viable embryo [68]. Effective coagulation control (through increased TTP and DCBD factors) is crucial for placental function, since an altered coagulation cascade can lead to placental abruption. Regulation of complement activation (CD59) prevents membrane attack complex -induced C9 polymerization that promotes adverse pore production on the cell surface [69]. The embryo and early pregnancy trophoblast are highly vulnerable to an oxygen rich environment. Thus, down-regulation of peroxidases and HSPs by PIF may support a protective role, as shown in the embryo and decidua $[26,29,32,33,37,42]$. This protection is amplified by the ATPB protein involved in ATP production, which, together with HBB, further protects against free oxygen and nitrogen radical species. Reduced KPYM levels prevent caspase-independent cell death. Clustering analysis indicated that beyond the central role of HLA-G and FOXP3, PIF also reduced the EGF receptor, which interacts with harmful LMNA and PDIA proteins. This is relevant, since PIF's pro-receptive effect on the decidua was negated by EGF [30]. Hence, the proteome analysis substantiates PIF's multifaceted role in regulating the activity of the trophoblast, acknowledging that it is a transformed cell line.

Both Th1 and Th2 type cytokines were up-regulated by PIF. The increase in IL-10, a prime Th2 cytokine, was induced by both P4 and PIF in JEG-3 cells. IL-10 may be secreted by both Th1 and Th2 type cells; its function is to balance pro- and anti-inflammatory signals [70-72]. IL-10 enhances HLA-G transcription in first trimester human trophoblast cultures $[73,74]$. In the endometrium PIF and P4 create a pro-inflammatory milieu by increasing IL$1 \beta$, IL-8, GM-CSF and IFN- $\gamma$ secretion to promote embryo implantation $[29,30,36]$. Elevated TGF- $\beta$ could promote IL-1-induced T-cell proliferation and trophoblast invasion by upregulating integrin expression, as shown for PIF in the endometrium, independent of P4. Thus, PIF-induced secretion of diverse cytokines, in contrast to P4, which affected only IL10, supports PIF-induced trophoblast interaction with the maternal milieu.

The current study is limited, since JEG-3 cytotrophoblastic cells and not primary trophoblastic cells were used. However, this model was validated with respect to the administration of P4, which was shown to be of physiologic value. In addition, exogenous PIF was administered. However, importantly, PIF targets the embryo and significant levels are present in the maternal circulation, which support the data generated with exogenous PIF administration $[25,26]$. These are in vitro observations and therefore data using PIF in an in vivo setting would help to substantiate its potential clinical utility in treatment of pregnancy disorders. Recent data showed that in an immune intact murine model PIF administration reduces foetal death due to LPS administration [75]. Spontaneous pregnancy loss was also lowered. In addition, PIF negated oxidative stress of cultured bovine IVF embryos induced by a protein-di-sulphide isomerase inhibitor. In presence of PIF more than two-fold increase in embryos reaching the blastocyst stage was noted [76, 77]. 


\section{Conclusion}

PIF promotes the expression of HLA-G, -C, -E and mildly -F which are critical for immunological tolerance in JEG-3 choriocarcinoma cells. The effect of PIF was found to be superior to that of P4 in terms of promoting expression of the HLAs and cytokines studied. By promoting P4 secretion and receptor expression, PIF potentiates the endogenous steroid's effect. PIF regulates the trophoblast proteome, promotes tolerance by increasing HLA-G and FoxP3+ levels and affects coagulation and complement, while it reduces the level of proteins involved in oxidative stress and protein misfolding. PIF-induced increase in Th1/ Th2 cytokine secretion favours trophoblast/maternal signaling. PIF successfully completed a Phase I FDA designated Fast-Track clinical trial for an autoimmune disease (Clinicaltrials. gov NCT02239562). Current data support comparable testing in early pregnancy disorders as well.

\section{Acknowledgements}

Professor I. L. Sargent for providing the JEG-3 cell line, Dr. G. Desoye for providing the ACH-3P cell line, and Dr. D. Geraghty for providing the anti-HLA-F clone 3D11. We thank Amy Carter, Stephanie Zinn and Amanda Roma for editorial assistance.

\section{Disclosure Statement}

ERB is BioIncept LLC CSO and PIF is patent protected. Other authors have no competing interests.

\section{References}

1 Zarnani AH, Moazzeni SM, Shokri F, Salehnia M, Dokouhaki P, Ghods R, Mahmoodi AR, Jeddi-Tehrani M: Microenvironment of the feto-maternal interface protects the semiallogenic fetus through its immunomodulatory activity on dendritic cells. Fertil Steril 2008;90:781-788.

2 Paidas MJ, Annunziato J, Romano M, Weiss L, Or R, Barnea ER: Pregnancy and Multiple Sclerosis (MS): A Beneficial Association. Possible therapeutic application of embryo-specific Pre-implantation Factor (PIF*). Am J Reprod Immunol 2012;68:456-464.

3 Barnea ER, Rambaldi M, Paidas MJ, Mecacci F: Reproduction and autoimmune disease: important translational implications from embryo-maternal interaction. Immunotherapy 2013;5:769-780.

4 Tincani A, Bompane D, Danieli E, Doria A: Pregnancy, lupus and antiphospholipid syndrome (Hughes syndrome). Lupus 2006;15:156-160.

5 Thellin 0, Coumans B, Zorzi W, Igout A, Heinen E: Tolerance to the foeto-placental 'graft': ten ways to support a child for nine months. Curr Opin Immunol 2000;12:731-737.

6 Beagley KW, Gockel CM: Regulation of innate and adaptive immunity by the female sex hormones oestradiol and progesterone. FEMS Immunol Med Microbiol 2003;38:13-22.

7 Barnea ER: Signaling between Embryo and Mother in Early Pregnancy: Basis for Development of Tolerance; in Carp HJA (ed) Recurrent Pregnancy Loss - Causes, Controversies, and Treatment. Boca Raton, Florida, CRC Press, 2014, pp 17-28.

8 Genbacev 0, Donne M, Kapidzic M, Gormley M, Lamb J, Gilmore J, Larocque N, Goldfien G, Zdravkovic T, McMaster MT, Fisher SJ: Establishment of human trophoblast progenitor cell lines from the chorion. Stem Cells 2011;29:1427-1436.

-9 Hanna J, Goldman-Wohl D, Hamani Y, Avraham I, Greenfield C, Natanson-Yaron S, Prus D, Cohen-Daniel L, Arnon TI, Manaster I, Gazit R, Yutkin V, Benharroch D, Porgador A, Keshet E, Yagel S, Mandelboim O: Decidual NK cells regulate key developmental processes at the human fetal-maternal interface. Nat Med 2006;12:1065-1074. 


\section{Cellular Physiology Cell Physiol Biochem 2017;43:2277-2296 \begin{tabular}{l|l|l|l} 
DOI: 101159/000484378 2017 The Author(s). Published by S. Karger AG, Basel & Diochem
\end{tabular} and Biochemistry Published online: October 27, 2017 www.karger.com/cpb}

Hakam et al.: Preimplantation Factor (PIF) Regulates HLA-G

10 Gregori S, Amodio G, Quattrone F, Panina-Bordignon P: HLA-G Orchestrates the Early Interaction of Human Trophoblasts with the Maternal Niche. Front Immunol 2015;6:128.

11 Lynge Nilsson L, Djurisic S, Hviid TV: Controlling the Immunological Crosstalk during Conception and Pregnancy: HLA-G in Reproduction. Front Immunol 2014;5:198.

12 Moffett A, Loke C: Immunology of placentation in eutherian mammals. Nat Rev Immunol 2006;6:584-594.

13 Barnea ER, Feldman D, Kaplan M: The Effect of Progesterone upon First Trimester Trophoblastic Cell Differentiation and Human Chorionic Gonadotropin Secretion. Hum Reprod 1991;6:905-909.

14 Yie SM, Xiao R, Librach CL: Progesterone regulates HLA-G gene expression through a novel progesterone response element. Hum Reprod 2006;21:2538-2544.

15 Jabeen A, Miranda-Sayago JM, Obara B, Spencer PS, Dealtry GB, Hayrabedyan S, Shaikly V, Laissue PP, Fernandez N: Quantified colocalization reveals heterotypic histocompatibility class I antigen associations on trophoblast cell membranes: relevance for human pregnancy. Biol Reprod 2013;89:94.

16 Shaikly V, Shakhawat A, Withey A, Morrison I, Taranissi M, Dealtry GB, Jabeen A, Cherry R, Fernandez N: Cell bio-imaging reveals co-expression of HLA-G and HLA-E in human preimplantation embryos. Reprod Biomed Online 2010;20:223-233.

-17 Spencer PS, Hakam SM, Laissue PP, Jabeen A, Jain P, Hayrabedyan S, Todorova K, Blanch A, McElhinney JM, Muhandiram N, Alkhatib S, Dealtry GB, Miranda-Sayago JM, Fernandez N: Key cellular components and interactive histocompatibility molecules regulating tolerance to the fetal allograft. Am J Reprod Immunol 2012;68:95-99.

18 Barnea ER, Oelsner G, Benveniste R, Romero R, DeCherney AH: Progesterone, Estradiol, and AlphaHuman Chorionic Gonadotropin Secretion in Patients with Ectopic Pregnancy. J Clin Endocrinol Metab 1986;62:529-531.

19 Morel Y, Roucher F, Plotton I, Goursaud C, Tardy V, Mallet D: Evolution of steroids during pregnancy: Maternal, placental and fetal synthesis. Ann Endocrinol (Paris) 2016;77:82-89.

-20 Barnea ER: Applying Embryo-Derived Immune Tolerance to the Treatment of Immune Disorders. Ann N Y Acad Sci 2007;1110:602-618.

21 Barnea ER: Insight into early pregnancy events: the emerging role of the embryo. Am J Reprod Immunol 2004;51:319-322.

22 Than NG, Paidas M, Mizutani S, Sharma SS, Padbury J, Barnea ER: Embryo-Placento-Maternal Interaction and Biomarkers: From Diagnosis to Therapy - A Workshop Report; Trophoblast Research, 2007, vol 21, pp S1-S4.

23 Stamatkin CW, Roussev RG, Stout M, Absalon-Medina V, Ramu S, Goodman C, Coulam CB, Gilbert RO, Godke RA, Barnea ER: PreImplantation Factor (PIF) correlates with early mammalian embryo developmentbovine and murine models. Reprod Biol Endocrinol 2011;9:63.

24 Stamatkin CW, Roussev RG, Stout M, Coulam CB, Triche E, Godke RA, Barnea ER: Preimplantation factor negates embryo toxicity and promotes embryo development in culture. Reprod Biomed Online 2011;23:517-524.

-25 Ramu S, Stamatkin C, Timms L, Ruble M, Roussev RG, Barnea ER: PreImplantation factor (PIF) detection in maternal circulation in early pregnancy correlates with live birth (bovine model). Reprod Biol Endocrinol 2013;11:105.

26 Barnea ER, Lubman DM, Liu YH, Absalon-Medina V, Hayrabedyan S, Todorova K, Gilbert RO, Guingab J, Barder TJ: Insight into PreImplantation Factor (PIF*) mechanism for embryo protection and development: target oxidative stress and protein misfolding (PDI and HSP) through essential RIKP [corrected] binding site. PLoS One 2014;9:e100263.

-27 Roussev RG, Dons'koi BV, Stamatkin C, Ramu S, Chernyshov VP, Coulam CB, Barnea ER: Preimplantation factor inhibits circulating natural killer cell cytotoxicity and reduces CD69 expression: implications for recurrent pregnancy loss therapy. Reprod Biomed Online 2013;26:79-87.

28 Paidas MJ, Krikun G, Huang SJ, Jones R, Romano M, Annunziato J, Barnea ER: A genomic and proteomic investigation of the impact of preimplantation factor on human decidual cells. Am J Obstet Gynecol 2010;202:459 e451-458.

29 Barnea ER, Kirk D, Paidas MJ: Preimplantation factor (PIF) promoting role in embryo implantation: increases endometrial integrin-alpha2beta3, amphiregulin and epiregulin while reducing betacellulin expression via MAPK in decidua. Reprod Biol Endocrinol 2012;10:50. 


\section{Cellular Physiology Cell Physiol Biochem 2017;43:2277-2296 \begin{tabular}{l|l|l} 
DOI: 101159/000484378 & $\begin{array}{l}\text { (c) 2017 The Author(s). Published by S. Karger AG, Basel } \\
\text { www.karger.com/cpb }\end{array}$
\end{tabular}}

Hakam et al.: Preimplantation Factor (PIF) Regulates HLA-G

-30 Duzyj CM, Paidas MJ, Jebailey L, Huang JS, Barnea ER: PreImplantation Factor (PIF*) promotes embryotrophic and neuroprotective decidual genes: effect negated by epidermal growth factor. J Neurodev Disord 2014;6:36.

-31 Barnea ER, Kirk D, Ramu S, Rivnay B, Roussev R, Paidas MJ: PreImplantation Factor (PIF) orchestrates systemic antiinflammatory response by immune cells: effect on peripheral blood mononuclear cells. Am J Obstet Gynecol 2012;207:313 e311-311.

-32 Barnea ER, Kirk D, Todorova K, McElhinney J, Hayrabedyan S, Fernandez N: PIF direct immune regulation: Blocks mitogen-activated PBMCs proliferation, promotes TH2/TH1 bias, independent of $\mathrm{Ca}(2+)$. Immunobiology 2015;220:865-875.

33 Barnea ER, Hayrabedyan S, Todorova K, Almogi-Hazan O, Or R, Guingab J, McElhinney J, Fernandez N, Barder T: PreImplantation factor (PIF*) regulates systemic immunity and targets protective regulatory and cytoskeleton proteins. Immunobiology 2016;221:778-793.

-34 Chen YC, Rivera J, Fitzgerald M, Hausding C, Ying YL, Wang X, Todorova K, Hayrabedyan S, Barnea ER, Peter K: PreImplantation factor prevents atherosclerosis via its immunomodulatory effects without affecting serum lipids. Thromb Haemost 2016;115:1010-1024.

-35 Azar Y, Shainer R, Almogi-Hazan O, Bringer R, Compton SR, Paidas MJ, Barnea ER, Or R: Preimplantation factor reduces graft-versus-host disease by regulating immune response and lowering oxidative stress (murine model). Biol Blood Marrow Transplant 2013;19:519-528.

-36 Shainer R, Almogi-Hazan O, Berger A, Hinden L, Mueller M, Brodie C, Simillion C, Paidas M, Barnea ER, Or R: PreImplantation factor (PIF) therapy provides comprehensive protection against radiation induced pathologies. Oncotarget 2016;7:58975-58994.

-37 Weiss L, Bernstein S, Jones R, Amunugama R, Krizman D, Jebailey L, Almogi-Hazan O, Yekhtin Z, Shiner R, Reibstein I, Triche E, Slavin S, Or R, Barnea ER: Preimplantation factor (PIF) analog prevents type I diabetes mellitus (TIDM) development by preserving pancreatic function in NOD mice. Endocrine 2011;40:41-54.

38 Weiss L, Or R, Jones RC, Amunugama R, JeBailey L, Ramu S, Bernstein SA, Yekhtin Z, Almogi-Hazan O, Shainer R, Reibstein I, Vortmeyer AO, Paidas MJ, Zeira M, Slavin S, Barnea ER: Preimplantation factor (PIF*) reverses neuroinflammation while promoting neural repair in EAE model. J Neurol Sci 2012;312:146-157.

-39 Shainer R, Azar Y, Almogi-Hazan O, Bringer R, Compton SR, Paidas MJ, Barnea ER, Or R: Immune Regulation and Oxidative Stress Reduction by Preimplantation Factor following Syngeneic or Allogeneic Bone Marrow Transplantation. Conference Papers in Medicine 2013;2013:1-8.

40 Mueller M, Zhou J, Yang L, Gao Y, Wu F, Schoeberlein A, Surbek D, Barnea ER, Paidas M, Huang Y: PreImplantation factor promotes neuroprotection by targeting microRNA let-7. Proc Natl Acad Sci U S A 2014;111:13882-13887.

-41 Mueller M, Schoeberlein A, Zhou J, Joerger-Messerli M, Oppliger B, Reinhart U, Bordey A, Surbek D, Barnea ER, Huang Y, Paidas M: PreImplantation Factor bolsters neuroprotection via modulating Protein Kinase A and Protein Kinase C signaling. Cell Death Differ 2015;22:2078-2086.

-42 Moindjie H, Santos ED, Loeuillet L, Gronier H, de Mazancourt P, Barnea ER, Vialard F, Dieudonne MN: Preimplantation factor (PIF) promotes human trophoblast invasion. Biol Reprod 2014;91:118.

-43 Barnea ER, Vialard F, Moindjie H, Ornaghi S, Dieudonne MN, Paidas MJ: PreImplantation Factor (PIF*) Endogenously Prevents Preeclampsia: Promotes Trophoblast Invasion and Reduces Oxidative Stress. J Reprod Immunology 2015;114:58-64.

44 Duzyj CM, Barnea ER, Li M, Huang SJ, Krikun G, Paidas MJ: Preimplantation factor promotes first trimester trophoblast invasion. Am J Obstet Gynecol 2010;203:402 e401-404.

45 Tilburgs T, Crespo AC, van der Zwan A, Rybalov B, Raj T, Stranger B, Gardner L, Moffett A, Strominger JL: Human HLA-G+ extravillous trophoblasts: Immune-activating cells that interact with decidual leukocytes. Proc Natl Acad Sci U S A 2015;112:7219-7224.

-46 Moindjie H, Dos Santos E, Gouesse R, Swierkowski-Blanchard N, Serazin V, Barnea ER, Vialard F, Dieudonne MN: PreImplantation Factor is an anti-apoptotic effector in human trophoblasts involving p53 signaling pathway. Cell Death Dis 2016;7:e2504.

47 Liu Z, Ruan HJ, Gu PQ, Ding WY, Luo XH, Huang R, Zhao W, Gao LJ: The Roles of p38 MAPK and ERK1/2 in Coplanar Polychlorinated Biphenyls-Induced Apoptosis of Human Extravillous Cytotrophoblast-Derived Transformed Cells. Cell Physiol Biochem 2015;36:2418-2432. 


\section{Cellular Physiology Cell Physiol Biochem 2017;43:2277-2296

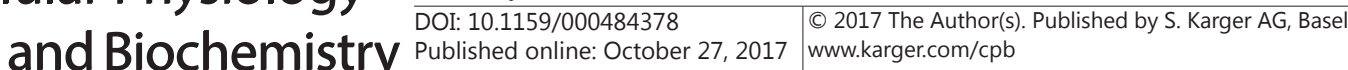

Hakam et al.: Preimplantation Factor (PIF) Regulates HLA-G

48 Shaikly VR, Morrison IE, Taranissi M, Noble CV, Withey AD, Cherry RJ, Blois SM, Fernandez N: Analysis of HLA-G in maternal plasma, follicular fluid, and preimplantation embryos reveal an asymmetric pattern of expression. J Immunol 2008;180:4330-4337.

49 Menier C, Saez B, Horejsi V, Martinozzi S, Krawice-Radanne I, Bruel S, Le Danff C, Reboul M, Hilgert I, Rabreau M, Larrad ML, Pla M, Carosella ED, Rouas-Freiss N: Characterization of monoclonal antibodies recognizing HLA-G or HLA-E: new tools to analyze the expression of nonclassical HLA class I molecules. Hum Immunol 2003;64:315-326.

-50 Palmisano GL, Contardi E, Morabito A, Gargaglione V, Ferrara GB, Pistillo MP: HLA-E surface expression is independent of the availability of HLA class I signal sequence-derived peptides in human tumor cell lines. Hum Immunol 2005;66:1-12.

51 Zhao L, Teklemariam T, Hantash BM: Reassessment of HLA-G isoform specificity of MEM-G/9 and 4H84 monoclonal antibodies. Tissue Antigens 2012;80:231-238.

52 Hakam SM: The Role of Soluble Factors Affecting the Major Histocompatibility Complex Class I Molecules in an in vitro Model of the Fetomaternal Interface: Philosophy. UK, University of Essex, 2016, Doctor of Philosophy, pp 188.

-53 Cooper JC, Dealtry GB, Ahmed MA, Arck PC, Klapp BF, Blois SM, Fernandez N: An impaired breeding phenotype in mice with a genetic deletion of beta-2 microglobulin and diminished MHC class I expression: role in reproductive fitness. Biol Reprod 2007;77:274-279.

54 Cherry RJ, Wilson KM, Triantafilou K, O’Toole P, Morrison IE, Smith PR, Fernandez N: Detection of dimers of dimers of human leukocyte antigen (HLA)-DR on the surface of living cells by single-particle fluorescence imaging. J Cell Biol 1998;140:71-79.

55 Sasse J, Gallagher SR: Staining proteins in gels. Curr Protoc Immunol 2004;Chapter 8:Unit 89.

56 Sasse J, Gallagher SR: Staining proteins in gels. Curr Protoc Mol Biol 2003;Chapter 10:Unit 1016.

57 Lipton MS, Pasa-Tolic L: Mass spectrometry of proteins and peptides: methods and protocols. Preface. Methods Mol Biol 2009;492:v.

58 Padliya ND, Wood TD: Improved peptide mass fingerprinting matches via optimized sample preparation in MALDI mass spectrometry. Anal Chim Acta 2008;627:162-168.

-59 Murthi P, Stevenson JL, Money TT, Borg AJ, Brennecke SP, Gude NM: Placental CLIC3 is increased in fetal growth restriction and pre-eclampsia affected human pregnancies. Placenta 2012;33:741-744.

-60 Hiby SE, Apps R, Sharkey AM, Farrell LE, Gardner L, Mulder A, Claas FH, Walker JJ, Redman CW, Morgan L, Tower C, Regan L, Moore GE, Carrington M, Moffett A: Maternal activating KIRs protect against human reproductive failure mediated by fetal HLA-C2. J Clin Invest 2010;120:4102-4110.

-61 Lee N, Goodlett DR, Ishitani A, Marquardt H, Geraghty DE: HLA-E surface expression depends on binding of TAP-dependent peptides derived from certain HLA class I signal sequences. J Immunol 1998;160:49514960.

62 Lee N, Llano M, Carretero M, Ishitani A, Navarro F, Lopez-Botet M, Geraghty DE: HLA-E is a major ligand for the natural killer inhibitory receptor CD94/NKG2A. Proc Natl Acad Sci U S A 1998;95:5199-5204.

-63 Hiby SE, Walker JJ, O'Shaughnessy K M, Redman CW, Carrington M, Trowsdale J, Moffett A: Combinations of maternal KIR and fetal HLA-C genes influence the risk of preeclampsia and reproductive success. J Exp Med 2004;200:957-965.

64 Fan M, Xu Y, Hong F, Gao X, Xin G, Hong H, Dong L, Zhao X: Rac1/beta-Catenin Signalling Pathway Contributes to Trophoblast Cell Invasion by Targeting Snail and MMP9. Cell Physiol Biochem 2016;38:1319-1332.

65 Li H, Han L, Yang Z, Huang W, Zhang X, Gu Y, Li Y, Liu X, Zhou L, Hu J, Yu M, Yang J, Li Y, Zheng Y, Guo J, Han J, Li L: Differential Proteomic Analysis of Syncytiotrophoblast Extracellular Vesicles from Early-Onset Severe Preeclampsia, using 8-Plex iTRAQ Labeling Coupled with 2D Nano LC-MS/MS. Cell Physiol Biochem 2015;36:1116-1130.

66 Huang QT, Chen JH, Hang LL, Liu SS, Zhong M: Activation of PAR-1/NADPH oxidase/ROS signaling pathways is crucial for the thrombin-induced sFlt-1 production in extravillous trophoblasts: possible involvement in the pathogenesis of preeclampsia. Cell Physiol Biochem 2015;35:1654-1662.

-67 Bhattacharyya S, Chaudhary J, Das C: Antibodies to hCG inhibit progesterone production from human syncytiotrophoblast cells. Placenta 1992;13:135-139.

68 Somerset DA, Zheng Y, Kilby MD, Sansom DM, Drayson MT: Normal human pregnancy is associated with an elevation in the immune suppressive CD25+ CD4+ regulatory T-cell subset. Immunology 2004;112:38-43. 


\section{Cellular Physiology Cell Physiol Biochem 2017;43:2277-2296

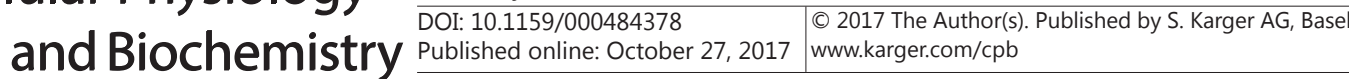

Hakam et al.: Preimplantation Factor (PIF) Regulates HLA-G

69 Zipfel PF, Skerka C: Complement regulators and inhibitory proteins. Nat Rev Immunol 2009;9:729-740.

70 Granot I, Gnainsky Y, Dekel N: Endometrial inflammation and effect on implantation improvement and pregnancy outcome. Reproduction 2012;144:661-668.

71 Challis JR, Lockwood CJ, Myatt L, Norman JE, Strauss JF, 3rd, Petraglia F: Inflammation and pregnancy. Reprod Sci 2009;16:206-215.

72 Chaouat G, Menu E, de Smedt D, Khrihnan L, Hui L, Assal Meliani A, Martal J, Raghupathy R, Wegmann TG: The emerging role of IL-10 in pregnancy. Am J Reprod Immunol 1996;35:325-329.

-73 Moreau P, Adrian-Cabestre F, Menier C, Guiard V, Gourand L, Dausset J, Carosella ED, Paul P: IL-10 selectively induces HLA-G expression in human trophoblasts and monocytes. Int Immunol 1999;11:803811.

74 Rizzo R, Hviid TV, Stignani M, Balboni A, Grappa MT, Melchiorri L, Baricordi OR: The HLA-G genotype is associated with IL-10 levels in activated PBMCs. Immunogenetics 2005;57:172-181.

75 Di Simone N, Di Nicuolo F, Marana R, Castellani R, Ria F, Veglia M, Scambia G, Surbek D, Mueller M, Barnea ER: PreImplantation Factor (PIF) prevents fetal loss by modulating LPS-induced inflammatory response. PLoS One 2017;12(7):e0180642

76 Goodale LF, Hayrabedyan S, Todorova K, Roussev R, Ramu S, Stamatkin C, Coulam C, Barnea ER, Gilbert RO: PreImplantation Factor (PIF) protects cultured embryos against oxidative stress: relevance for recurrent pregnancy loss (RPL) therapy. Oncotarget 2017:1-14.

77 Barnea, E.R., et al.: Immune regulatory and neuroprotective properties of preimplantation factor: From newborn to adult. Pharmacol Ther 2015;156:10-25. 